\title{
SUMMARY REPORT OF FUEL ROD DISPLACEMENT SENSOR FOR LOFT
}

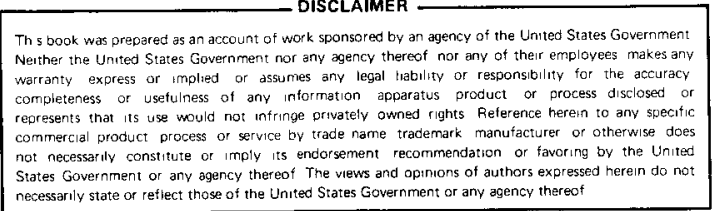

\section{Hanford Engineering Development Laboratory}

T.R. Billeter

January 1980 


\section{DISCLAIMER}

This report was prepared as an account of work sponsored by an agency of the United States Government. Neither the United States Government nor any agency Thereof, nor any of their employees, makes any warranty, express or implied, or assumes any legal liability or responsibility for the accuracy, completeness, or usefulness of any information, apparatus, product, or process disclosed, or represents that its use would not infringe privately owned rights. Reference herein to any specific commercial product, process, or service by trade name, trademark, manufacturer, or otherwise does not necessarily constitute or imply its endorsement, recommendation, or favoring by the United States Government or any agency thereof. The views and opinions of authors expressed herein do not necessarily state or reflect those of the United States Government or any agency thereof. 


\section{DISCLAIMER}

Portions of this document may be illegible in electronic image products. Images are produced from the best available original document. 


\section{CONTENTS}

Page

FIGURES

TABLES

iv

1.0 SUMMARY AND CONCLUSIONS 1

2.0 SUBJECT OF REPORT 3

$\begin{array}{ll}3.0 & \text { SENSOR REQUIREMENTS }\end{array}$

4.0 SENSOR DESCRIPTION 6

5.0 SIGNAL CONDITIONING ELECTRONICS

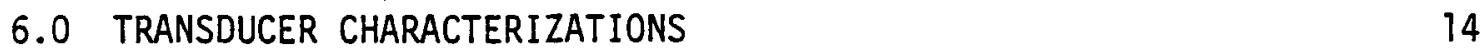

$\begin{array}{lll}7.0 & \text { OPERATING CHARACTERISTICS } & 17\end{array}$

$\begin{array}{lll}7.1 & \text { Calibration } & 17\end{array}$

7.2 Temperature Transient 24

$\begin{array}{ll}7.3 & \text { Short Term Stability } \\ 7.4 & 24\end{array}$

7.4 Transients Provided by Blowdown in Autoclave 28

7.5 Time Response 32

7.6 Quench Test 35

$\begin{array}{lll}7.7 & \text { Irradiation Tolerance } & 35\end{array}$

$\begin{array}{ll}\text { APPENDIX A } & 41\end{array}$

$\begin{array}{ll}\text { REFERENCES } & 42\end{array}$

DISTRIBUTION $\quad$ D-1 
FIGURES

FIGURE

Page

2.1 Clamshel1 Oven Used for Calibration of Displacement Sensor.

4.1 Outline Depiction of Qualification Displacement Sensor for LOFT. Dimensions in Inches.

4.2 Pictorial of Displacement Measuring Instrumentation.

6.1 Calibration of Production LVDT using Sensing Core From Qualification Unit.

6.2 Calibration of Production LVDT. Production Core Used.

6.3 Variation of Signal Output with Temperature for Production LVDT and Qualification Sensing Core.

6.4 Variation of Signal Output with Temperature for Production LVDT and Production Sensing Core.

7.1 Calibration of Qualification Sensor.

7.2 Least Squares Straight Line Fit for Data of Figure 7.1.

7.3 Temperature Variation during Time of Transient in Oven.

7.4 Signal Response of Qualification Sensor for Applied Fast Temperature Change.

7.5 Short Term Stability of Signal Output for Qualification Sensor.

7.6 Variation of Signal Output of Qualification Sensor for Autoclave Blowdown.

7.7 Rate of Temperature Change for Blowdown Test of Figure 7.6.

7.8 Variation of Signal Output for Slow Increase of Sensor Temperature.

7.9 Long Term Signal Output Stability for LVDT in Autoclave at $650^{\circ} \mathrm{F}$.

7.10 Response of the Sensor for Rapid Displacement of the Sensing Core. T Represents 10\% to 90\% Time Response. 
FIGURES (Cont'd)

FIGURE

Page

7.11 Displacement Sensor Output Signal Variation for Quench of Sensor Temperature from 800 to $200^{\circ} \mathrm{F}$.

7.12 Time Sequence of Signal Output for Temperature Quench of Figure 7.11 . 


\section{TABLES}

Page

3.1 Displacement Sensor Performance Requirements and Operating Environment.

8

4.1 Construction Materials for LVDT Displacement Sensor. 
TC-1619

\author{
SUMMARY REPORT OF FUEL ROD \\ DISPLACEMENT SENSOR FOR LOFT
}

\title{
1.0 SUMMARY AND CONCLUSIONS
}

Qualification tests conducted for a period of 700 hours of each of three displacement measuring (LVDT) sensors confirmed applicability of the design for use in the Loss-of-Fluid-Test (LOFT) reactor. Operationally, the sensor satisfies all specified requirements for LOFT. Even for imposed temperature transients at rates up to $100^{\circ} \mathrm{F} / \mathrm{s}$, the indicated displacement remained within the allowed maximum error band of $\pm 10 \%$ of reading. The 0.625 -inch $0 . D$. by 5.5-inch long sensor exhibited a linearly related signal output variation for displacement variations of up to 1 -inch range. Long term operation at temperatures of $100^{\circ} \mathrm{F}$ to $800^{\circ} \mathrm{F}$ caused no perceptible permanent change of operating characteristics. Furthermore, the severe and varied test rigor imposed on the displacement sensor during qualification tests justifies the following conclusions:

- All qualification sensors yielded linear variations of signal output with displacement changes for a range of one inch and exhibited a change of sensitivity of less than $5 \%$ over the temperature range of 100 to $800^{\circ} \mathrm{F}$.

- For imposed temperature transients, by use of either laboratory ovens or an autoclave, the maximum measurement error of $2 \%$ of reading remained less than the allowed value ( $\pm 10 \%$ of reading) for inaccuracy of LOFT displacement sensors.

- Thermal shielding of the sensor as provided by the installation design within the LOFT reactor should further improve displacement measurement accuracy, especially during temperature transients. 
- The sensor speed of response to rapid displacements of the core easily satisfied the specified $100 \mathrm{millisecond}$ requirement for LOFT

-Vibrations expected to occur during a LOFT transient should incur onty minimal spurious signal response, as vibration tests at reactor system frequencies caused no discernable signals superimposed on the quiescent value.

- Signal output voltage of the sensor/signal conditioning remained constant during long term stability tests, indicating negligible permanent signal drift.

- Because short term noise has an amplitude of approximately $0.5 \mathrm{milli-}$ volts, the displacement sensor should resolve rod length variations as small as 1 milliinch.

- Operating reliability of the sensor and conditioning electronics has been proven by subjecting each of the three test units to 700 hours of testing, sometimes with the sensor in severe environments.

As a result of diagnostic tests performed with the production version of the transducer these additional conclusions resulted:

- As compared with the qualification transducer, the larger temperaturedependent sensitivity of the production unit relates directly to characteristics of the sensing core.

- To better assure uniformity of operating characteristics, the sensing cores (and their encapsulating tube) for all LVDTs provided for LOFT should be manufactured using controlled annealing and metal working techniques and from a single billet of tool steel. 
- As finally installed in the LOFT fuel bundle, specific sensing cores and transducer coils should be paired identical with their pairing for calibration.

\subsection{SUBJECT OF REPORT}

This report describes physical and operational characteristics and qualification testing of displacement measurement instrumentation intended for use in the LOFT reactor. Loss of reactor coolant fluid will cause a rapid increase of temperature of the fuel rods resulting in their expansion. Three of the total number of fuel rods will be instrumented to permit evaluation of the magnitude and time sequence of rod elongation. Technical specifications and operating environment for the required displacement sensor influenced the decision to use a linear variable differential transformer (LVDT) for the application.

Based on development test results, five sensors were purchased from a single vendor for qualification tests. The test plan required at least three qualification sensors to withstand the total test rigor. Multiple iterations of each test were conducted during a total test period of 700 hours, the final 200 hours in an autoclave.

Qualification tests require the imposition of both stable and rapidiy changing environments. Calibrations, noise tests, and some temperature transient tests occur with the sensor installed within a laboratory oven as shown in Figure 2.1. Depressurization tests require use of an autoclave.

During qualification testing, data is acquired and plotted using a HP-3052A system. For calibrations, precise core positions depend on use of a digital stepper motor driving a rotary to linear mechanical motion translator. Temperature measurements originate from Type $K$ thermocouples attached to the sensor or other monitored assemblies.

Briefly, the test series included the following described procedures. 


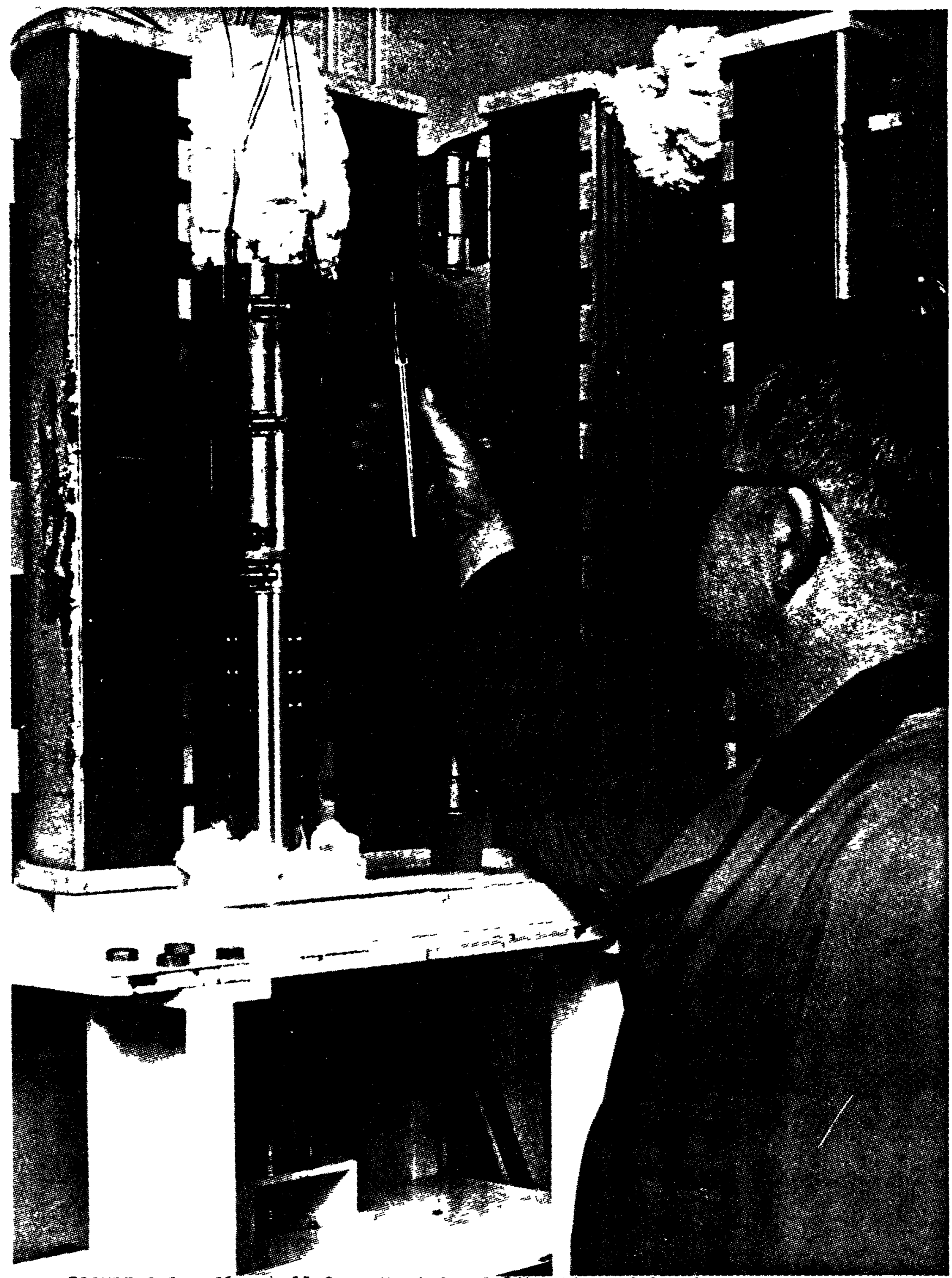

FIGURE 2.1. Clamshell Oven Used for CaTibration of Displacement Sensor. 
Calibration of the sensor for incremental displacements of 0.1-inch for a range of one inch and at temperatures from 100 to $800^{\circ} \mathrm{F}$ at $100^{\circ} \mathrm{F}$ increments.

For temperature change at rates as rapid as possible, vary the temperature immediately adjacent to the sensor between $650^{\circ} \mathrm{F}$ and $325^{\circ} \mathrm{F}$.

For constant displacements of $0.1,0.5$, and 1.0-inch each maintained for about two minutes, and at a sensor temperature of either 75 or $650^{\circ} \mathrm{F}$, measure the variation of output signal.

For a constant displacement of 0.5 -inches, measure the output voltage as pressurized water, initially at 2700 psig and $650^{\circ} \mathrm{F}$, is exhausted at depressurization rates up to $-105 \mathrm{psi} / \mathrm{s}$.

Test mechanical integrity of sensor by maintaining $75^{\circ} \mathrm{F}$ water at a pressure of 3125 psig for 15 minutes.

Displace sensing core as rapidly as possible through the total one-inch range. Determine the resultant 10 to $90 \%$ time response by measuring output voltage during the core movement.

Vibrate the sensor at accelerations of $0.5 \mathrm{G}$ for 40 seconds and of $2.0 \mathrm{G}$ for 100 milliseconds. Frequency of the vibrations shall occur at 40 to $50 \mathrm{~Hz}$.

At an initial temperature of $800^{\circ} \mathrm{F}$, cool the sensor as rapidly as possible to $200^{\circ} \mathrm{F}$.

The dominant reason for performing these tests concerns the requirements to provide (for the LOFT reactor) instruments of known operational characteristics, reproducibility, and reliability. However, the described displacement sensor should be usable in other applications at temperatures up to $800^{\circ} \mathrm{F}$ and pressures up to 2500 psig. 


\subsection{SENSOR REQUIREMENTS}

Functionally, the specified displacement sensor provides a measurement of elongation or contraction of the fuel rod length. This measurement is useful for predicting the mechanical dynamics of a nuclear fuel bundle during loss of coolant fluid. Inside the reactor, the sensor will be mounted inside a thermal shield cannister attached to an orifice plate. For much of its service life, the sensor will operate at the design pressure of 2000 psig and $650^{\circ} \mathrm{F}$. During imposed transients, pressure and temperature of the water or steam surrounding the sensor will undergo rapid variations. Table 3.1 delineates important technical specifications for the sensor.

\subsection{SENSOR DESCRIPTION}

The LVDT outlined in Figure 4.1 operates on the principle of mutual inductance between primary and secondary windings of a transformer. The transducer consists of a primary and two secondary windings inductively coupled via a mechanically separate soft iron core (sensing core). At a primary excitation frequency of $10 \mathrm{kHz}$, the primary induces a voltage, dependent upon the position of the core, into each secondary coil. The identical and symmetrically displaced (relative to the primary coil) secondary coils are connected in series opposition, thus null output voltage results for the sensing core axially centered between the secondary coils. As the core moves off-center, a net positive or negative voltage of magnitude proportional to the core offset results. Demodulation of the resulting ac voltage yields a dc output signal proportional to the position of the sensor core relative to the two secondary coils.

The coils, wound on a common cylindrical form, are enclosed in a $0.625-$ inch $0 . D$. by 5.5 -inch long cylindrical hermetically sealed Inconel envelope. A 0.093 -inch 0. D. by 2.75 -inch long soft iron core enclosed in a 12.9-inch long by 0.190 -inch 0.D. cylinder attached to the fuel rod moves along the central axis of the sensor coils as the fuel rod elongates during the reactor blowdown. A sixteen foot long, 1/16-inch 0.0 . dual conductor, stainless 


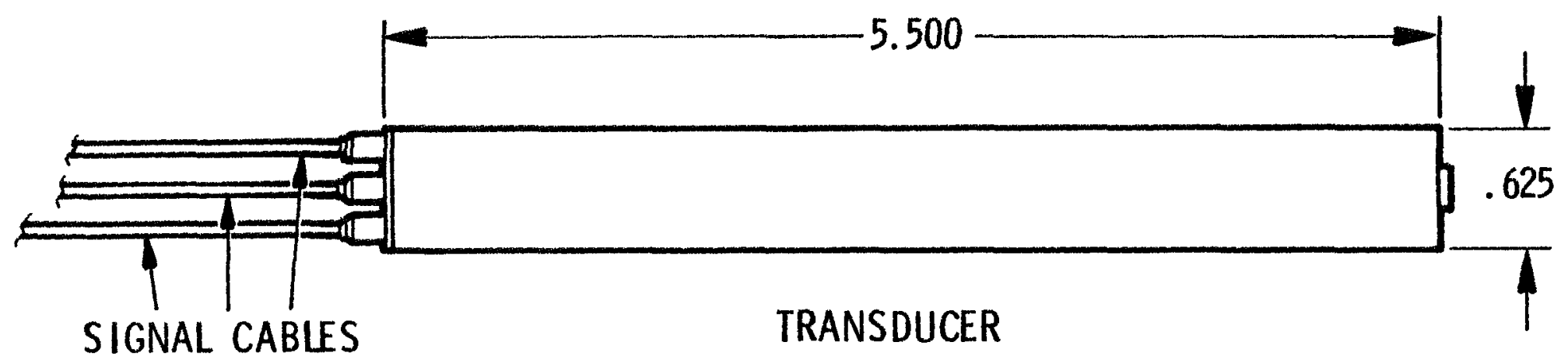

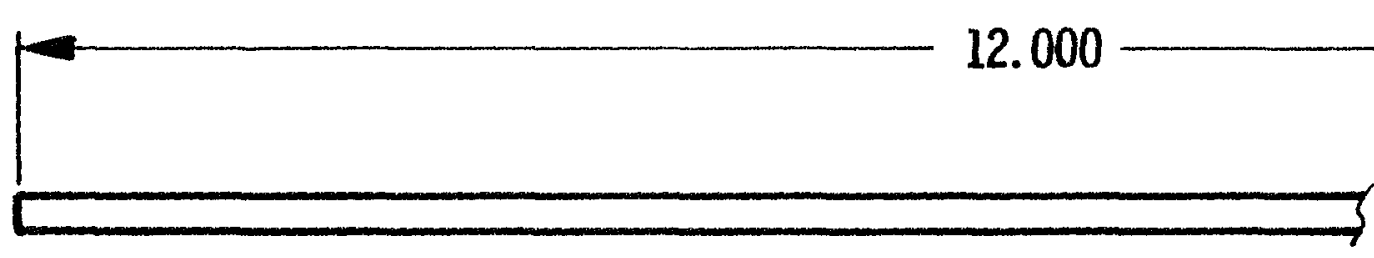

SENSING CORE

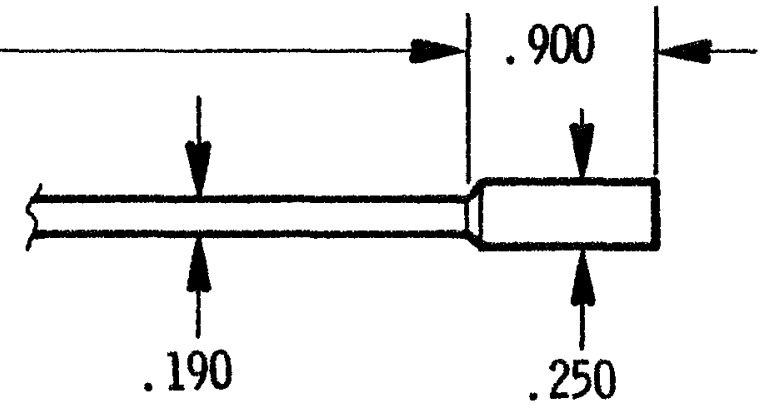

HEDL 7907-178

FIGURE 4.1. Outline Depiction of Qualification Displacement Sensor for LOFT Dimensions in Inches. 
TABLE 3.1

DISPLACEMENT SENSOR PERFORMANCE

REQUIREMENTS AND OPERATING ENVIRONMENT

\section{Performance:}

Range: $\quad$ Zero to 1.0 inch

Accuracy: $\quad \pm 10 \%$ of reading or \pm 0.020 inch, whichever is larger

Resolution: $\quad \pm 0.004$ inch or less

Response Time: 100 millisecond or less ( $10 \%$ to $90 \%$ of final value)

Operating Environment:

Media: $\quad$ LOFT water chemistry

Radiation: $\quad 2 \times 10^{13} \mathrm{n} / \mathrm{cm}^{2} \mathrm{sec}$.

$2 \times 10^{8} \mathrm{R} / \mathrm{hr}$

Pressure: $\quad$ Atmosphere to $13.8 \mathrm{MPa}$ (2000 psig)

$\frac{\mathrm{dp}}{\mathrm{dt}}=722 \mathrm{kPa} / \mathrm{sec}(105 \mathrm{psi} / \mathrm{sec})$

Temperature: $\quad 70$ to $650^{\circ} \mathrm{F}$

$$
800^{\circ} \mathrm{F} \text { for } 100 \text { seconds }
$$

$\frac{\mathrm{dT}}{\mathrm{dt}}=225^{\circ} \mathrm{F} / \mathrm{sec}$ 
steel sheathed magnesia-insulated cable attaches to each of the three coils. A pictorial (Figure 4.2) of the sensor, three attached signal cables, and signal conditioning electronics shows the sensing core being positioned within the coil assembly.

Individual coils are wound in a .020 -inch 0.D. coaxial configuration of a 0.006-inch copper conductor enclosed by magnesia insulation and a stainless steel sheath. The primary coil consists of 200 turns, whereas each secondary coil has 100 turns. Secondaries are designated either "Secondary Forward" or "Secondary Aft" depending on their proximity to the end of the sensor with the three cable terminations.

Materials of construction of major assemblies of the LVDT listed in Table 4.1 comprise metals and insulators exhibiting tolerance to irradiation in a thermal flux reactor.

\subsection{SIGNAL CONDITIONING ELECTRONICS}

The signal conditioning electronics selected for use with the transducer is the Schaevitz Electronics Co. Model CAS-100 (T.C.) which includes signal feedback circuitry to maintain the primary excitation electromagnetic field strength at a value sufficient to produce a constant magnitude of the sum of the secondary output voltages. As a consequence, amplitude of the difference of the two secondary voltages remains proportional to the sensing core displacement for most operating environments. Specifically, the temperature compensating signal conditioning electronics will yield increased measurement accuracy in the actual operating environment of LOFT for the following reasons:

- During development and qualification tests of the LVDT, temperature compensating electronics yielded data easily within specified accuracies.

- The environment and physical configuration of components existant during calibrations by the vendor do not simulate conditions occurring during tests in LOFT. To accomodate these additional variations, compensating electronics are required. 


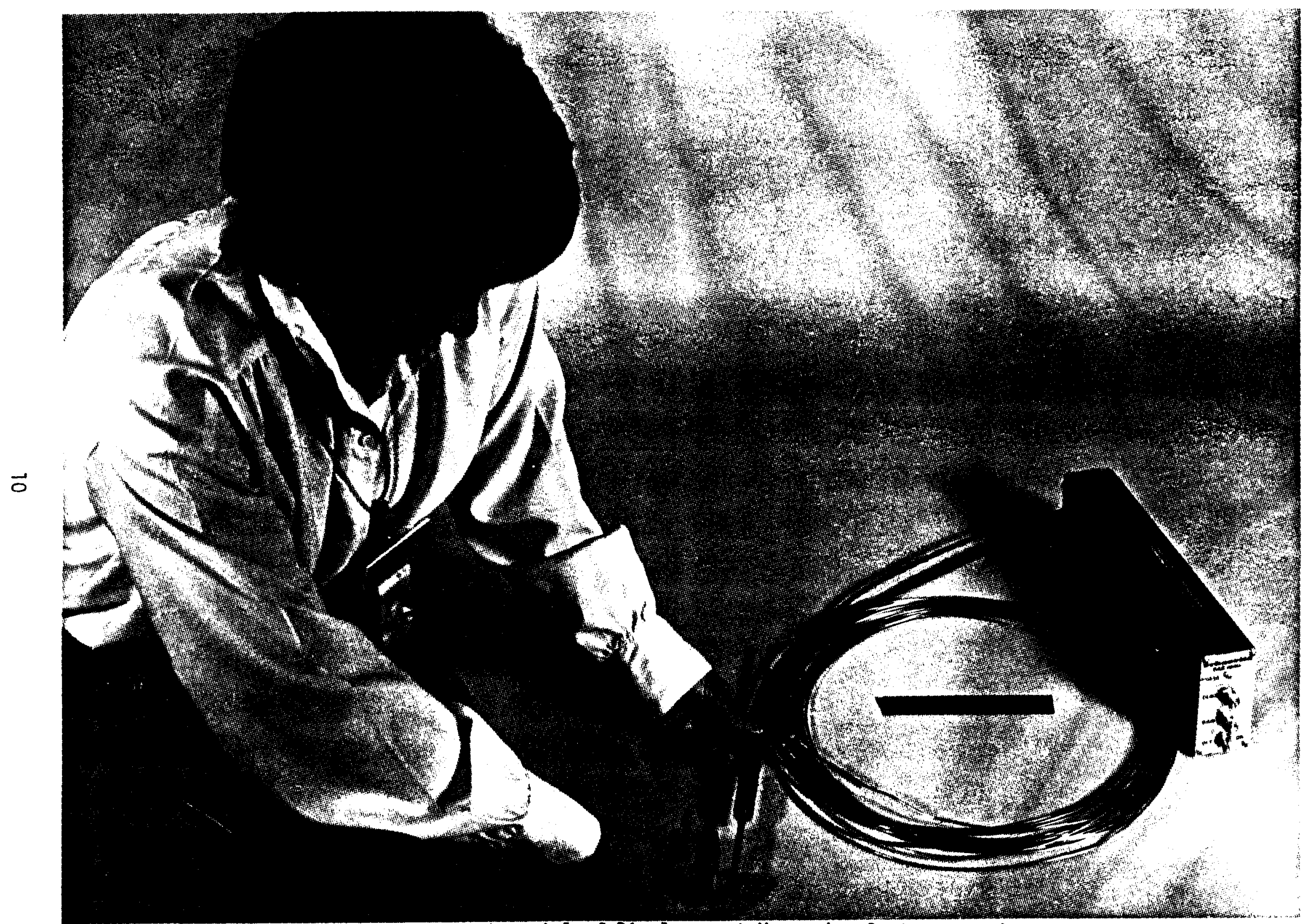

FIGURE 4.2. Pictorial of Displacement Measuring Instrumentation. 
TABLE 4.1

CONSTRUCTION MATERIALS

FOR LVDT DISPLACEMENT SENSOR

\section{Coil Assembly}

$\begin{array}{ll}\text { Ceramic Sleeve: } & 94 \% \text { Alumina } \\ \text { Coil Retainer: } & \text { Incone] } 625 \\ \text { Winding Tube: } & \text { Inconel 625 } \\ \text { Ceramic Cement: } & \text { Cotronics } 901 \\ \text { Ceramic Insulator: } & 99.5 \% \text { Alumina } \\ \text { Retaining Tube: } & \text { Stainless Stee1 } 321 \\ \text { Wire Retainer: } & \text { Inconel } 625 \\ \text { Termination } & \\ \quad \text { Retainer: } & \text { Inconel } 718 \\ \text { Coil Wire (Coax): } & \begin{array}{l}\text { Copper with .02\% Zirconium, } \\ \text { Magnesia, SS } 304\end{array}\end{array}$

\section{Cable/Bulkhead Assembly}

Signal Cable:

Cable Ferrule:

Cable Bulkhead:

Strain STeeves:

Coil Retainer/

Sheath:

Cable Sealant:
Inconel Clad Copper, Magnesia, SS 316

Incone1 625

Inconel 625

SS 304

Incone1 625

GTyptol (outside radiation zone)

Sensing Core Assembly

$\begin{array}{ll}\text { Core: } & \text { SAE-01 Tool Steel } \\ \text { Mounting Fastener: } & \text { Inconel 625 } \\ \text { Plug: } & \text { Inconel 625 } \\ \text { Insulation: } & \text { Ceramic Paper }\end{array}$

Materials Resume'

Inconel 625, 718

Stainless Steel 304, 316, 321, SAE-01

Copper $/ .02 \%$ Zirconium

Alumina $\left(\mathrm{AT}_{2} \mathrm{O}_{3}\right)$

Magnesia (MgO)

Cotronics 901 Cement

Ceramic Paper

Glyptol 
- Long-term permanent changes of cable characteristics or permeability of the sensing core can only be countered with the use of electronics with the compensating circuitry.

- Changes of electrical characteristics of the transducer or of signal cables as caused by radiation effects should be effectively neutralized with use of compensation electronics.

- Compensation improves linearity over the displacement range.

- Presently unpredicted effects on sensor physical characteristics may occur during LOFT tests. Those changes could be counteracted by using compensated electronics; in contrast, they would surely not be countered by use of uncompensated electronics.

Physically, the electronics package measured 2-inch $\times 4$-inch $\times 12-1 / 4-i n c h$ with an eight-spade terminal strip at the rear and adjustable potentiometers designated "PHASE", "ZERO", and "GAIN" on the faceplate. Connection to the transducer is accomplished by attaching the transducer signal cable conductors as specified below:

P2: Clear colored, primary lead

PI: Blue colored, primary lead

S2: Blue colored, secondary aft lead

CT: Both clear leads of secondaries

S1: Blue colored, secondary forward lead

Eo: Output dc voltage.

The braid sheath of all three signal cables is terminated at the chassis ground spade lug.

Adjustment of the signal conditioning for operation of the displacement measuring system follows the routine described below: 
1. Insert the power plug into a power receptacle with line voltage compatible with power requirements of the electronics.

2. Set ON-OFF switch to the ON position.

3. To ensure stability, allow unit to warm for 30 minutes before proceeding.

4. Adjust the internal $10 \mathrm{~K}$ potentiometer (RT6) to obtain $3.0 \mathrm{Vrms}$ excitation at $\mathrm{P} 1$ and $\mathrm{P} 2$ with the voltmeter low or ground probe connected to terminal P2.

5. Turn the GAIN control completely counterclockwise. (Minimum Gain).

6. Adjust ZERO control to achieve an output of zero Vdc.

7. Turn the GAIN control to approximately two turns clockwise.

8. Move the transducer core to obtain an output of zero Vdc. This is the transducer null position from which displacements are measured.

9. Displace the core from its null position to approximately $50 \%$ of full scale, and adjust the phase control for peak dc output. (An additional phase control is provided internally if unable to reach peak output.) If peak dc output exceeds $\pm 8 \mathrm{Vdc}$, reduce the gain setting and trim the phase adjustment.

10. Check the zero position by returning the transducer to its previous zero position. If an output other than zero Vdc exists, repeat step eight (8).

11. Adjust the gain control for a \pm 8 Vdc output. 
12. Check the full scale end points and adjust the zero control for balanced end point outputs.

\subsection{TRANSDUCER CHARACTERIZATIONS}

Although each transducer will exhibit individual electrical characteristics, typical values possibly useful for troubleshooting have been ascertained. Recognizing that the values noted herein depend upon the cable, as well as the transducer characteristics, caution must be exercised to avoid fallacious conclusions based on a single measurement.

Many of the tests described in this section were performed to ascertain the reason for an observed threefold increase of variation of temperaturedependent sensitivity for the production LVDT as compared with the qualification transducers.

\section{Electrical Characterizations:}

1. Insulation Resistance:

$$
\begin{array}{ll}
\text { Development Unit: } & >1.5 \times 10^{9} \Omega\left(75^{\circ} \mathrm{F}\right) \\
\text { Qualification Unit: } & >10^{9} \Omega\left(75^{\circ} \mathrm{F}\right) \\
\text { Production Unit: } & >3.2 \times 10^{6} \Omega\left(75^{\circ} \mathrm{F}\right) \\
& >1.3 \times 10^{6} \Omega\left(700^{\circ} \mathrm{F}\right)
\end{array}
$$

2. Coil/Cable dc Resistance:

\begin{tabular}{lcccc} 
& Wire Size (in.) & Cable (ohms) & & Coil (ohms) \\
\cline { 2 - 3 } Development & .008 & 8 & 8 \\
Production & .006 & 32 & 14 \\
Qualification & .004 & 8 & 26
\end{tabular}


3. Vector Impedance at $10 \mathrm{kHz}$ and $75^{\circ} \mathrm{F}$.

\begin{tabular}{|c|c|c|}
\hline Qualification Unit & $\begin{array}{l}\text { Conductor } \\
\text { to Conductor (ohms) }\end{array}$ & $\begin{array}{r}\text { Conductors } \\
\text { to Sheath (oh } \\
\end{array}$ \\
\hline Primary & $42.50+9^{\circ}$ & $2500 \div-90^{\circ}$ \\
\hline Secondary Fwd. & $300+9.5^{\circ}$ & 3200 e $-90^{\circ}$ \\
\hline Secondary Aft. & $300+9.5^{\circ}$ & $32000-90^{\circ}$ \\
\hline \multicolumn{3}{|l|}{ Production Unit } \\
\hline Primary & $550+5^{\circ}$ & 2400 a $-90^{\circ}$ \\
\hline Secondary Fwd. & $490+7.5^{\circ}$ & $3100 \bigcirc-90^{\circ}$ \\
\hline Secondary Aft. & $430+6^{\circ}$ & $3100 @-90^{\circ}$ \\
\hline
\end{tabular}

4. Magnetic Anomoloy with Temperature.

The output waveforms of the secondaries of the transducer should remain undistorted sine waves within the operating temperature range.

5. Sensitivity Variation within 75 to $650^{\circ} \mathrm{F}$ Temperature Range:

$\begin{array}{ll}\text { Development: } & \sim 17 \% \\ \text { Qualification: } & \sim 8 \% \\ \text { Production: } & \sim 18 \%\end{array}$

The production unit exhibits a monotonic increasing sensitivity with temperature increases. In contrast, the qualification unit has a more complex variation of sensitivity with temperature.

6. Simulation of Cable Resistance of Production Unit.

The production unit signal cables have a higher resistance (by a factor of four) than the qualification cables. Lumped resistances were added in series with the primary and secondary coils of the qualification unit to simulate the conditions existant for the production unit. Because 
of the operation of the compensating electronics, the added resistances caused only negligible change of operating characteristics.

7. Secondary Complex Voltages.

The complex voltage of the secondary coils was measured as temperature was varied. Primary voltage is used as the phase reference of a PAR Model 5204 lock-in amplifier. Core position is static at maximum negative displacement $\left(=0.5-\right.$ in. $\left._{\text {. }}\right) S_{1}$ ard $S_{2}$ are secondary forward and aft vector voltages, respectively.

\begin{tabular}{|c|c|c|}
\hline Temp. $\left({ }^{\circ} \mathrm{F}\right)$ & $s_{1}-s_{2}$ (qual. uait) & $s_{1}-s_{2}$ (prod. unit) \\
\hline 80 & .1456 e $178.5^{\circ}$ & -- \\
\hline 125 & -- & .0962 ○ $166.2^{\circ}$ \\
\hline 150 & $.1487 \bigcirc 180.3^{\circ}$ & -- \\
\hline 200 & $.1506 @ 180.7^{\circ}$ & $.0962 @ 162^{\circ}$ \\
\hline 250 & $.1518 \odot 181.9^{\circ}$ & -- \\
\hline 300 & $.1525 @ 179.6^{\circ}$ & $.10050163 .5^{\circ}$ \\
\hline 350 & $.1503 @ 180.8^{\circ}$ & $.1027 @ 164.5^{\circ}$ \\
\hline 400 & $.1487 @ 182.7^{\circ}$ & $.10480165 .3^{\circ}$ \\
\hline 450 & .1499 @ $183^{\circ}$ & $.1072 @ 165.9^{\circ}$ \\
\hline 500 & $.1515 @ 184.1^{\circ}$ & $.1094 @ 166.4^{\circ}$ \\
\hline 550 & $.153 @ 183.8^{\circ}$ & .1117 ○ $166.9^{\circ}$ \\
\hline 600 & $.1522 \Leftrightarrow 183^{\circ}$ & $.1141 @ 167.3^{\circ}$ \\
\hline 650 & $.1563 @ 183.6^{\circ}$ & $.1168 @ 167.7^{\circ}$ \\
\hline
\end{tabular}

8. Interchanging Coil/Core Components.

When used with the production unit coil assemblies, the qualification sensing cores significantly reduce the variation of sensitivity with temperature. It therefore appears that the magnetic properties of the qualification sensor cores have a temperature dependence which significantly contributes to the observed desirable sensitivity/temperature characteristic of the qualification transducers. 
As a result of the detailed diagnostic testing, the significant difference between qualification and production LVDTs was shown to be the sensing core. When used with the production transducer coil assembly, the qualification core (S/N 8227-0-05) yielded calibration data (Figure 6.1 shows a $4.5 \%$ change of sensitivity) consistent with data exhibited during qualification tests. In contrast, the same production coil assembly yielded data as shown in Figure 6.2 when calibrated with the production sensing core. It has also been noted that qualification cores yield the complex temperature/output voltage characteristic of Figure 6.3. Production cores yield a monotonically increasing output signal for temperature increases as shown in Figure 6.4.

\subsection{OPERATING CHARACTERISTICS}

Tests noted in Section 1.0 have been performed using three qualification sensors. Data typical of that series of tests is described in this section. Although some of the constituents of the production and qualification LVDTs differ, the operating characteristics of each is expected to be nearly the same. A detailed description of qualification tests has been previously reported. 1

\subsection{Calibration}

At each $100^{\circ} \mathrm{F}$ temperature increment from 100 to $800^{\circ} \mathrm{F}$, displacement of the core between extremes of the range at 0.1 -inch increments yields a variation of signal output as shown in Figure 7.1. The transducer exhibits a linear characteristic, with sensitivity remaining nearly constant for any temperature in the test range as may be confirmed by referring to a plot of the straight line fit which follows the calibration summary. For example, a least squares straight line fit (Figure 7.2 ) of the calibration data shows that data at the extremes of the range $(-0.5$-inch and 0.5 -inch) deviate from the best fit by less than +.011 -inch and -.008 -inch. These deviations equate to maximum inaccuracies of $+2.2 \%$ and $-1.6 \%$ of the values given by the least squares fit straight line. Consequently, the displacement indicated by the LVDT should be within the (LOFT) specified maximum allowable error at any sensor 


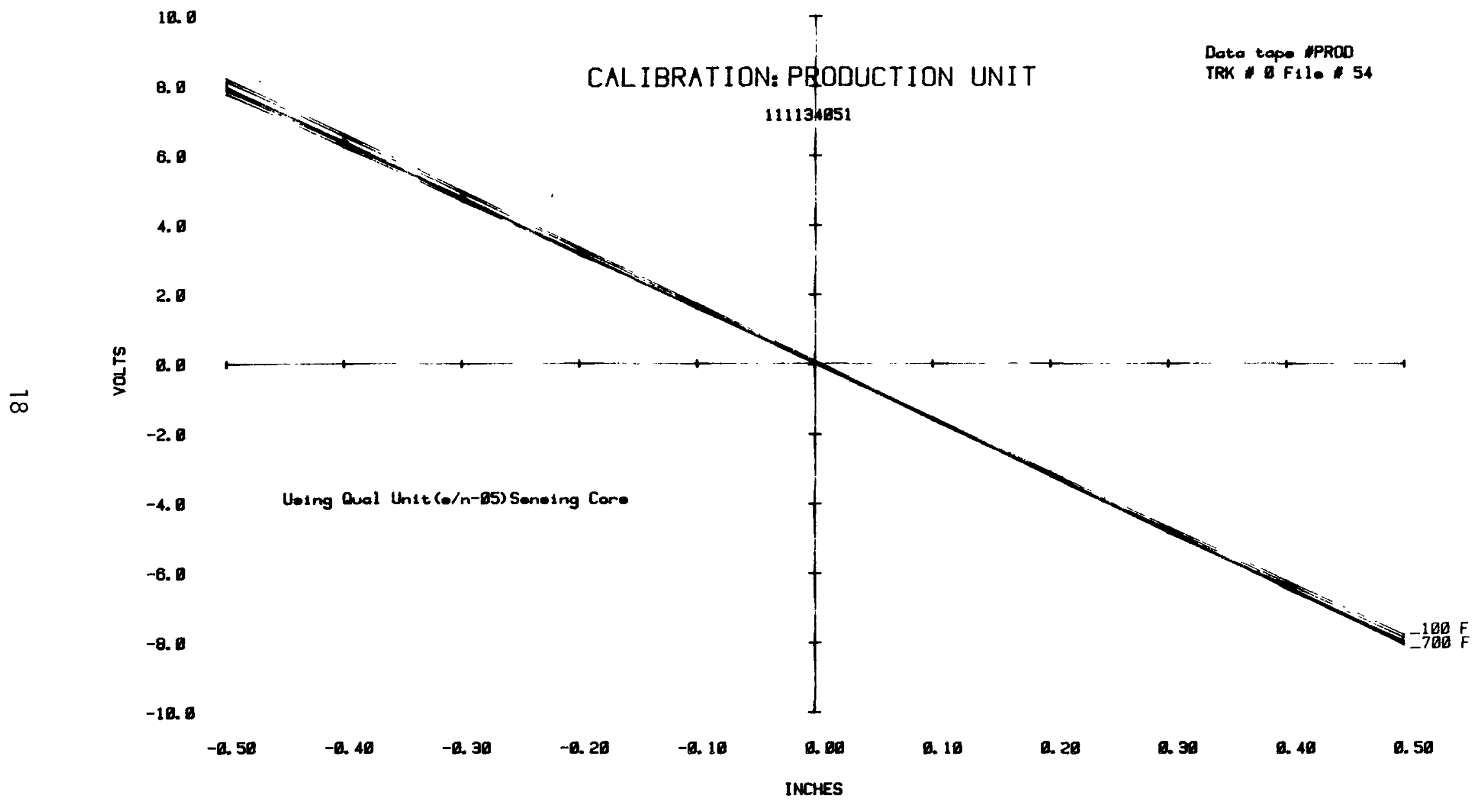

FIGURE 6.1. Calibration of Production LVDT Using Sensing Core from Qualification Unit. 


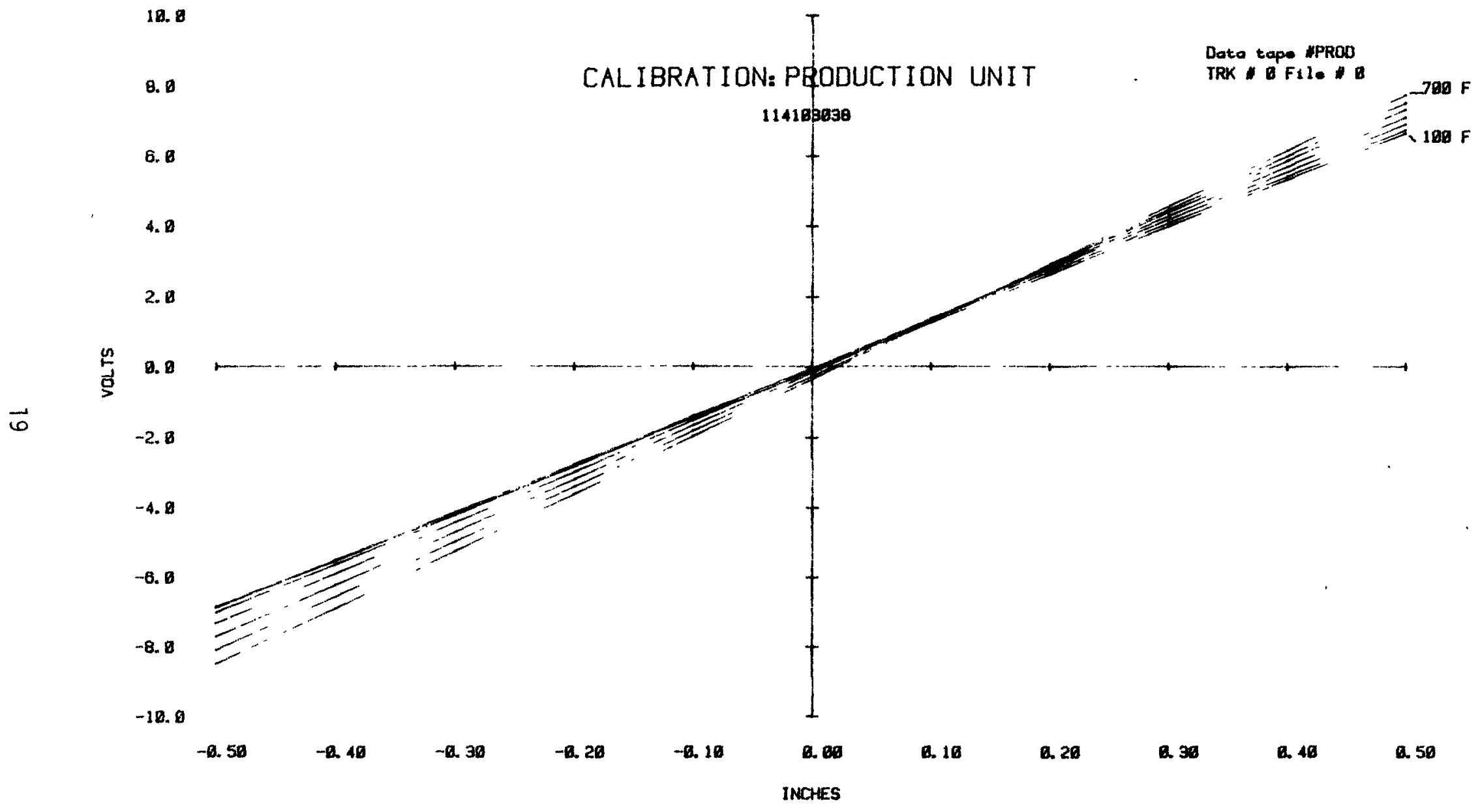

FIGURE 6.2. Calibration of Production LVDT. Production Core Used. 


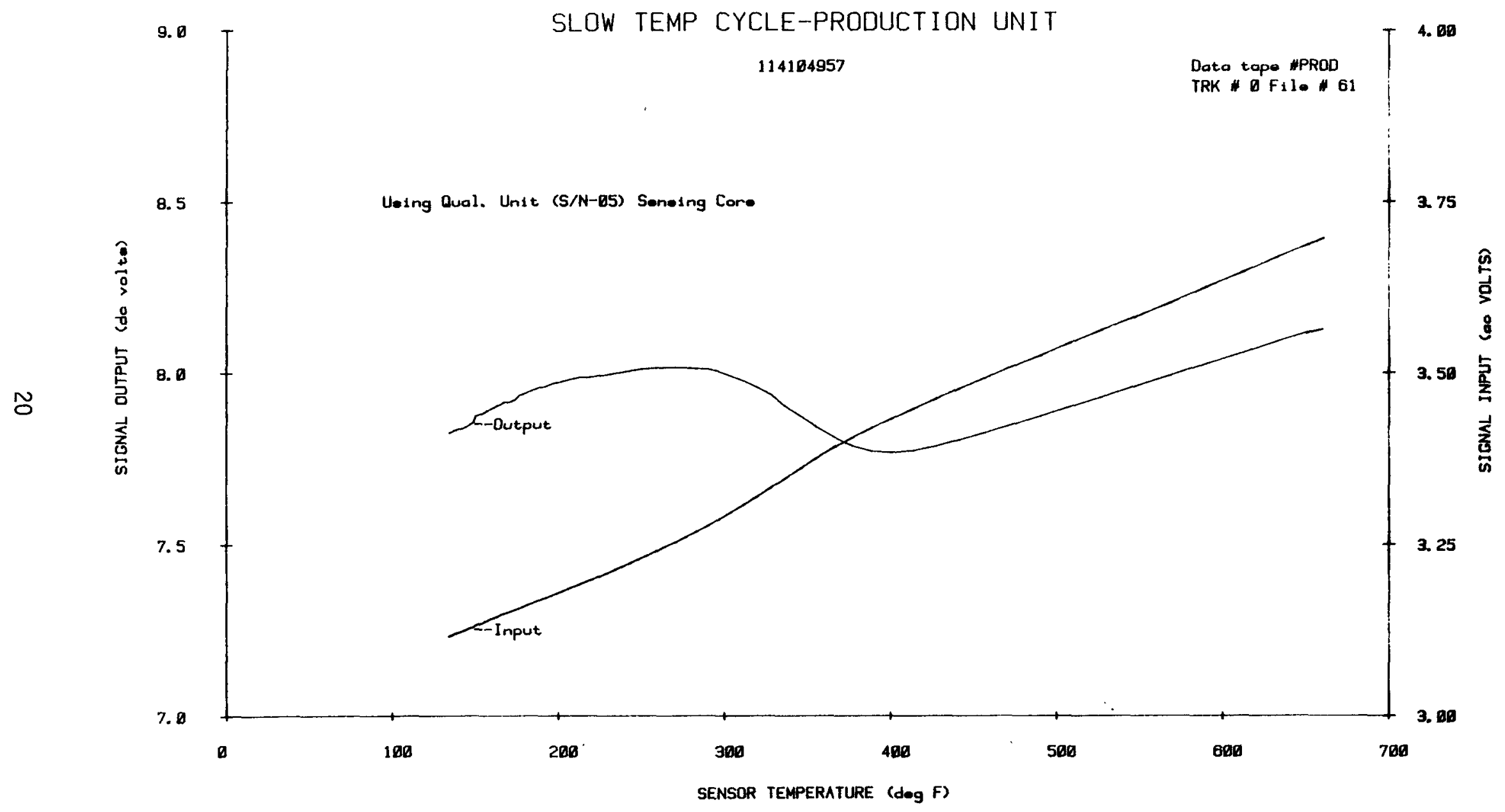

FIGURE 6.3. Variation of Signal Output with Temperature for Production LVDT and Qualification Sensing Core. 


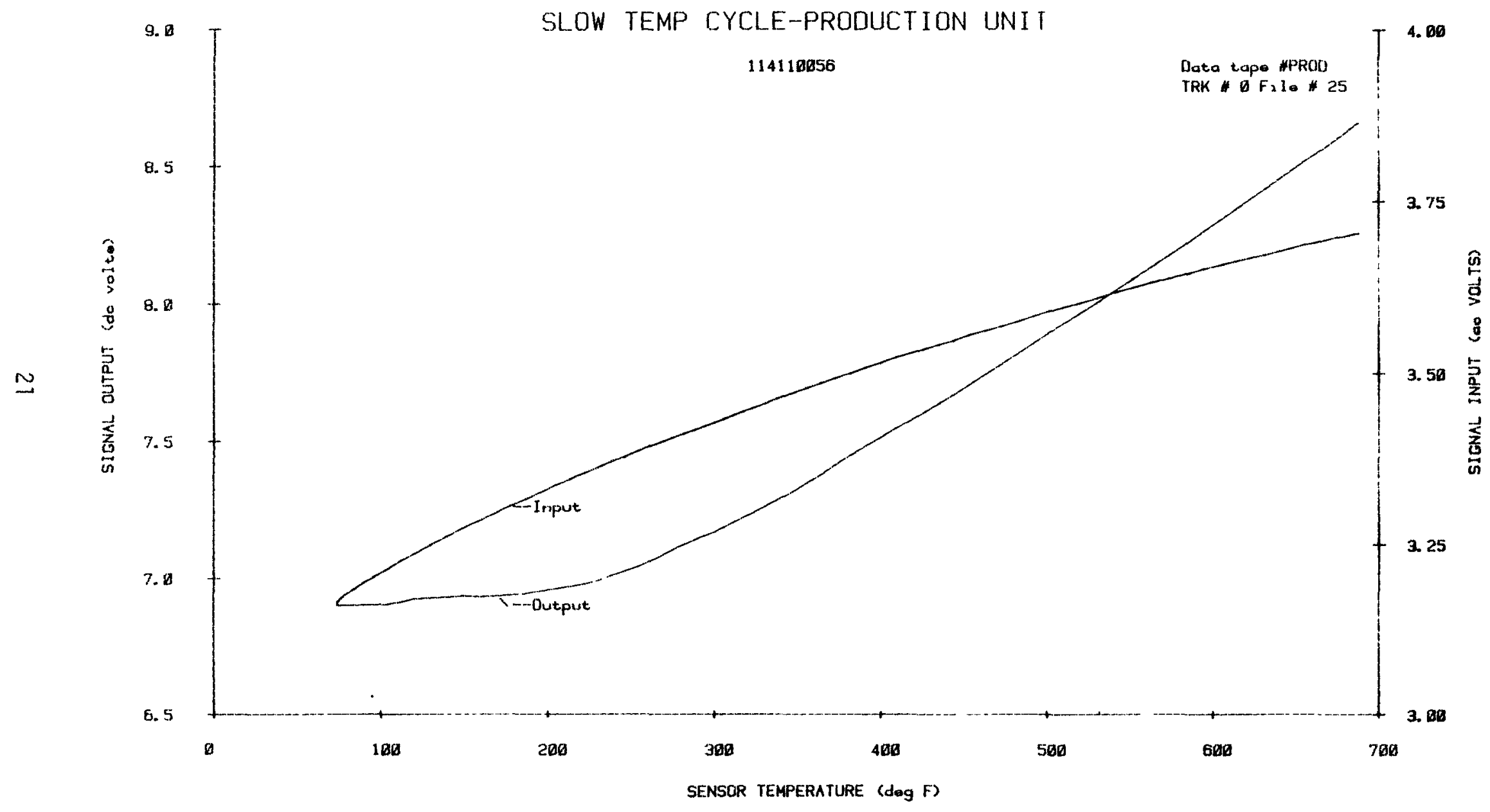

FIGURE 6.4. Variation of Signal Output with Temperature for Production LVDT and Production Sensing Core. 


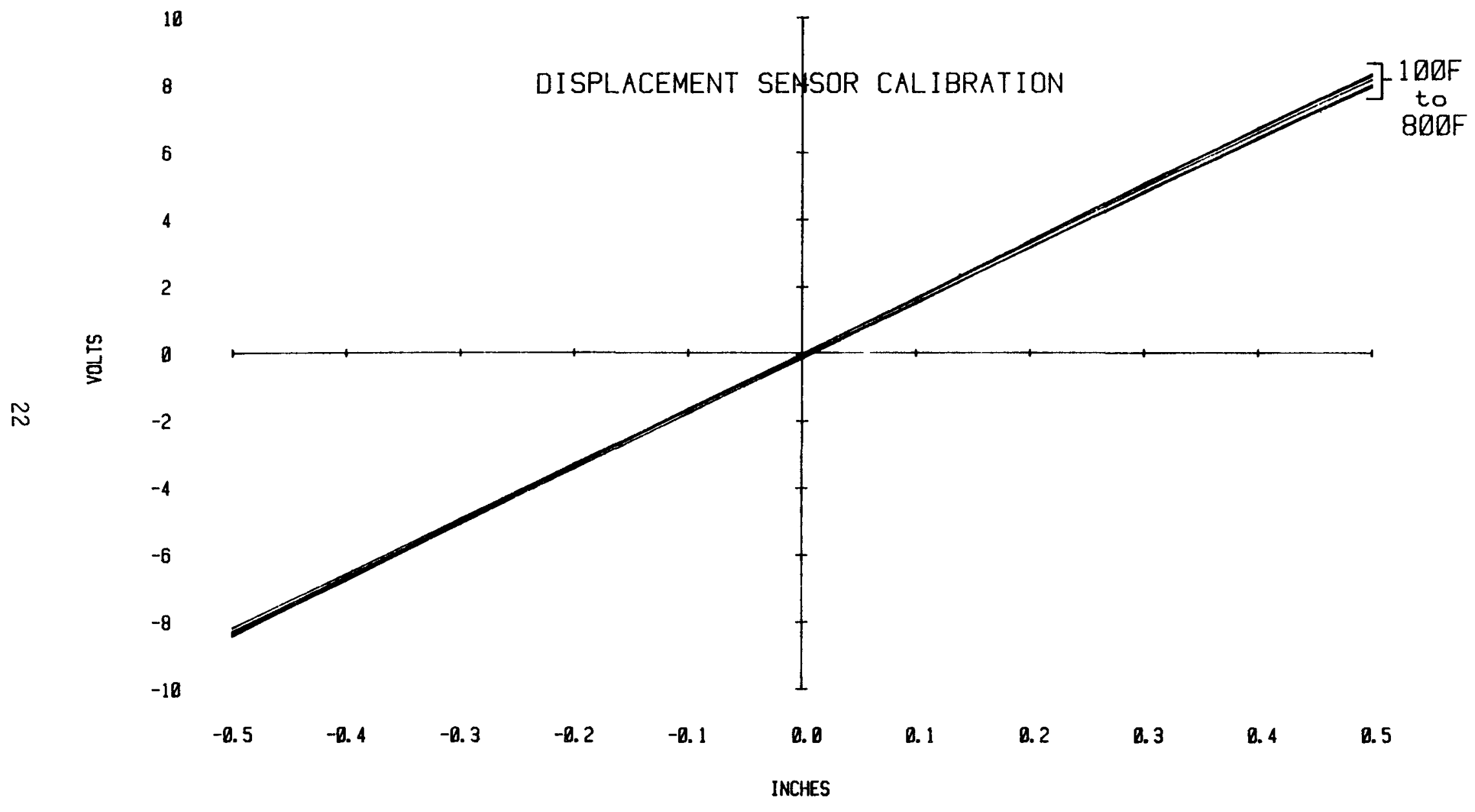

FIGURE 7.1. Calibration of Qualification Sensor. 


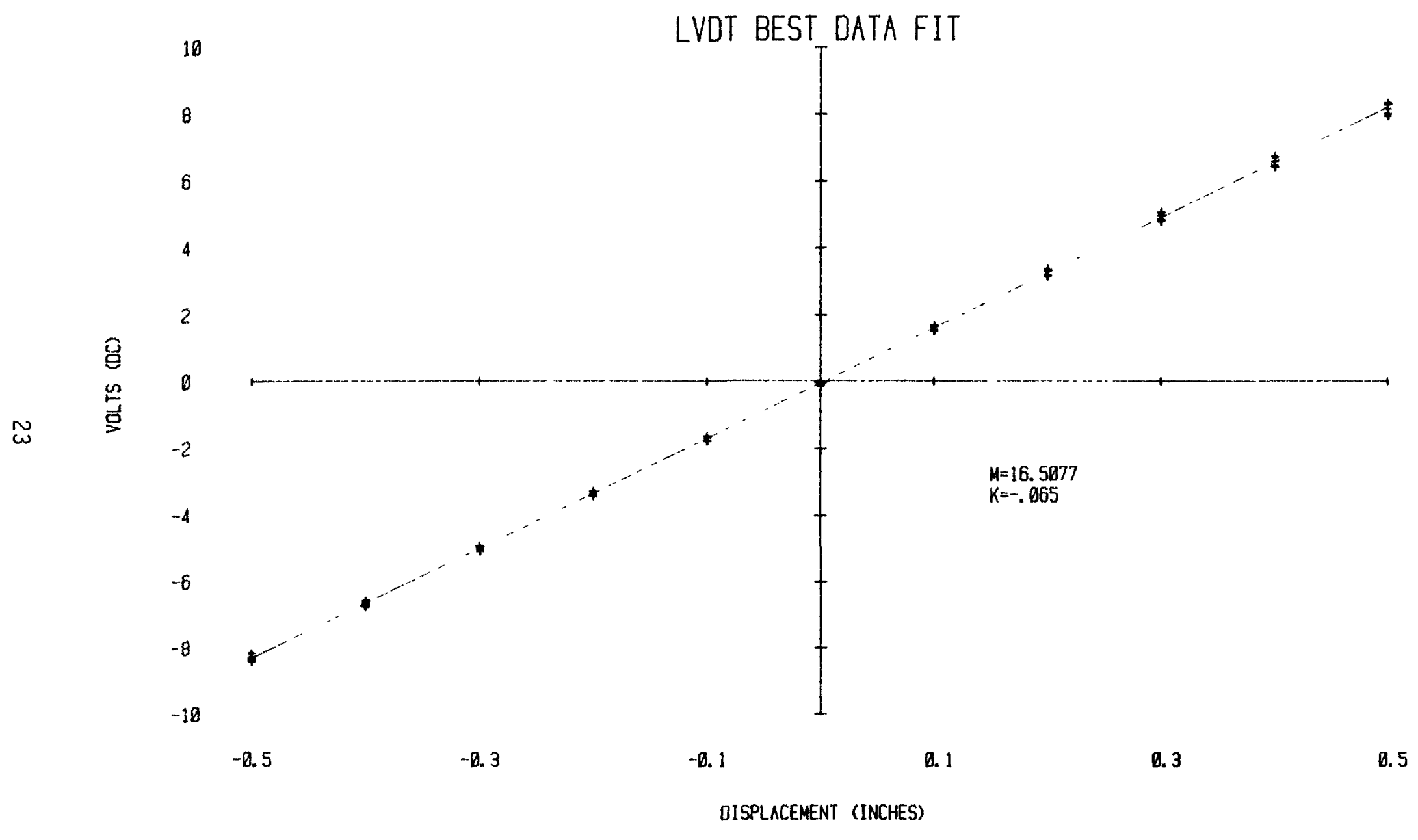

FIGURE 7.2. Least Squares Straight Line Fit for Data of Figure 7.1. 
temperature within the range of 100 to $800^{\circ} \mathrm{F}$. Multiple iterations of the calibration obtained periodically throughout the initial 500 hours of testing confirmed operational stability of the sensors, as similarity of data obtained from each of the iterations indicates.

\subsection{Temperature Transient}

For this test, positioning of two tube ovens collinearly enabled the rapid displacement of the test article along a quartz tube between one oven at $300^{\circ} \mathrm{F}$ and another at $650^{\circ} \mathrm{F}$. Norma $11 \mathrm{y}$, the test sequence began and ended with the sensor at the lower temperature, and at the higher temperature for an intermediate time period. Type $K$ thermocouples, one attached directly to the sensor body and another within 1/4-inch of the sensor envelope measure tem-perature of the sensor and of its adjacent medium. The core remains in a static position -- mechanically fixed to the sensor body. For these conditions, Figure 7.3 portrays the time sequence of sensor temperature and the effect upon signal output (Figure 7.4) of temperature variations at rates up to $138^{\circ} \mathrm{F} / \mathrm{s}$. The maximum signal change equals about $1 \%$ of reading, equivalent to an indicated displacement variation of .005-inch.

\subsection{Short Term Stability}

Figure 7.5 illustrates the variation of output signal for the core positioned staticaliy (at 0.1-, 0.5-, and 0.9-inch) and the sensor temperature at ambient or at about $800^{\circ} \mathrm{F}$. Because of minute movement of the core relative to the sensor body and of electrical noise inherent in the signal conditioning, the output signal varies by a maximum of 0.0005 volts. Each data point represents the difference of the output voltage at two consecutive data acquisition times differing by 13 seconds. A11 sensors exhibited short term stability necessary to obtain high resolution measurements of displacement during transient tests. 




FIGURE 7.3. Temperature Variation During Time of Transient in Oven. 


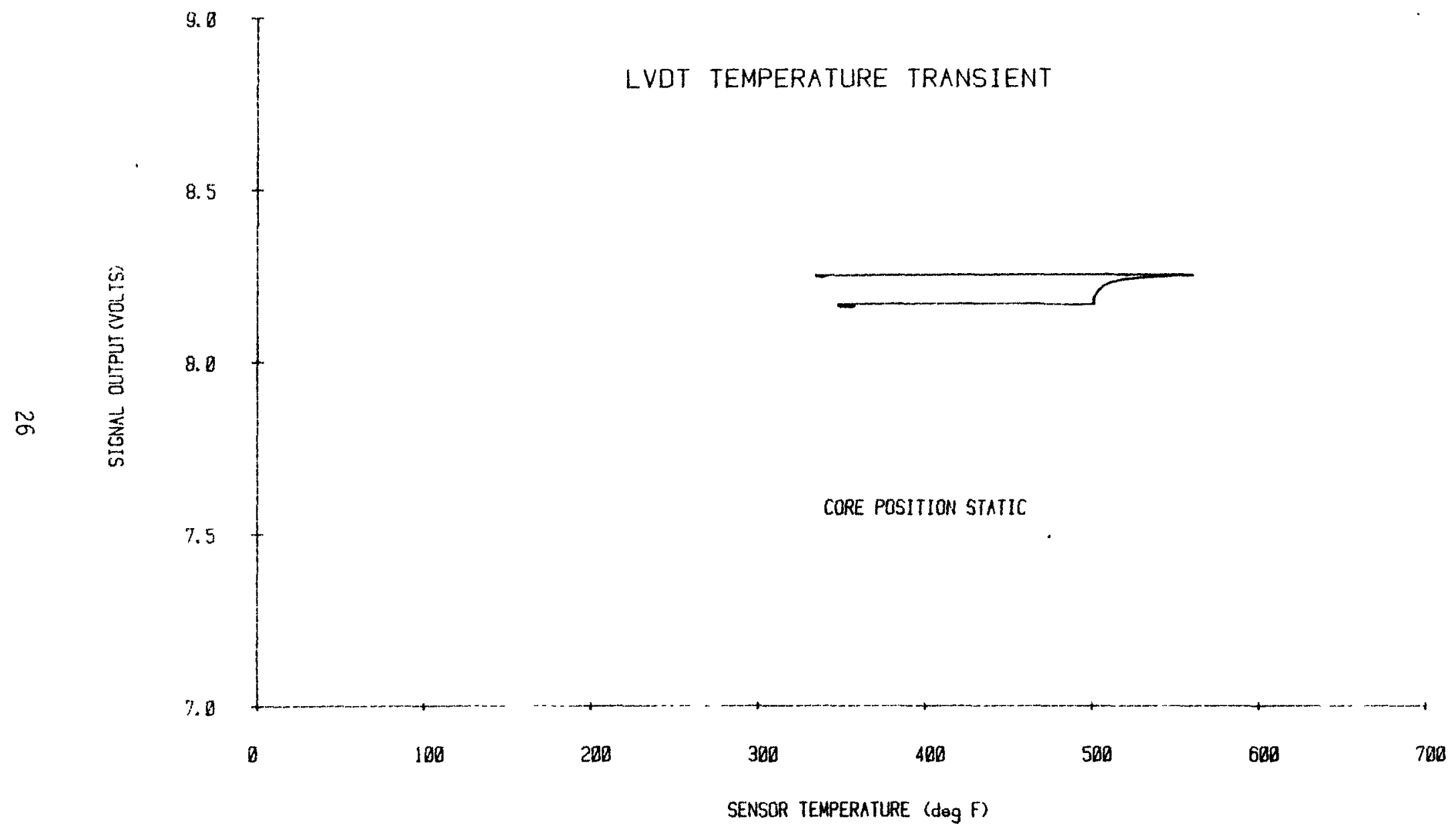

FIGURE 7.4. Signal Response of Qualification Sensor for Applied Fast Temperature Change. 


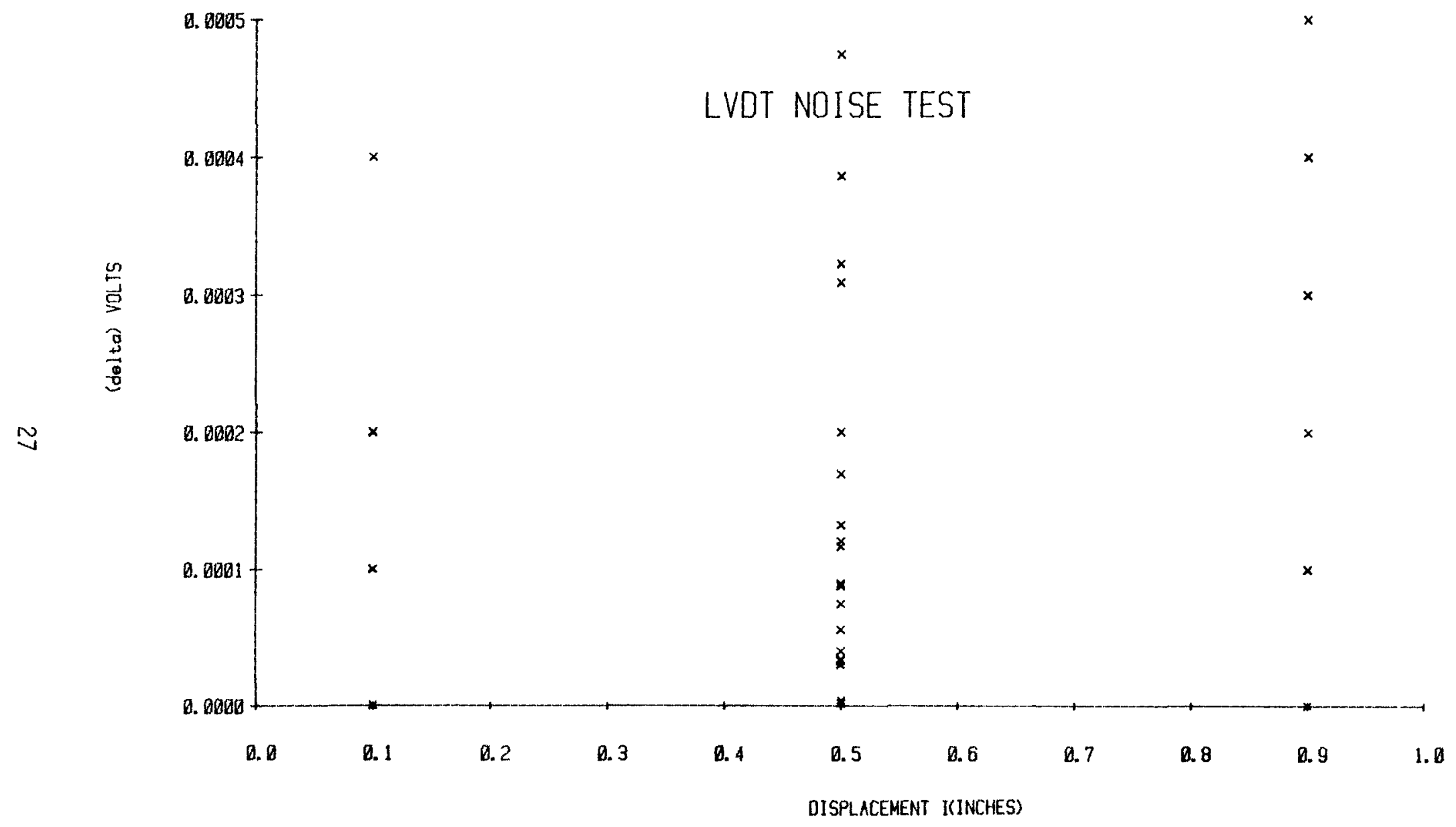

FIGURE 7.5. Short Term Stability of Signal Output for Qualification Sensor. 


\subsection{Transients Provided by Blowdown in Autoclave}

This test most nearly approximates environmental conditions expected to exist during actual use of the displacement sensor in LOFT. However, because of the complexity of remotely adjusting the core position of the sensor when mounted inside the autoclave, a constant core position (with respect to the body) is maintained for this test. Maximum rate depressurization for the 6.4 liter autoclave, initially filled with water at $650^{\circ} \mathrm{F}$ and $2700 \mathrm{psig}$, causes a temperature decrease of 200 to $300^{\circ} \mathrm{F}$ within about 15 seconds.

Rate of expulsion of water/steam depends upon the effective area of the exhaust orifice. Most blowdowns were conducted with the maximum attainable exhaust orifice area, although some were rate limited by restricting the exhaust area. For the majority of blowdowns, the exhaust valve was closed and the autoclave feed water pump activated immediately after depressurization. Output signal amplitude variations measured during the blowdown transient and for the ensuing 23 minutes - while water refilled the autoclave - relate to the effect upon the displacement transducer of temperature gradients near the sensor envelope.

For autoclave depressurization, the displacement sensor output signal varies due to a rapid variation of temperature. Figure 7.6 shows a typical response for depressurization at the rates of temperature change (Figure 7.7 ) sustained by the sensor. At a nominal sensitivity of 16 volts/in., the maximum variation of voltage during transients corresponds to .016-inches of displacement, or an inaccuracy of $3.2 \%$ of reading. Even for temperature rates of $60^{\circ} \mathrm{F} / \mathrm{s}$ as shown during the initial phases of the blowdown, the sensor remained within the accuracy limit specified for the LOFT displacement sensor.

It is evident from the data plot of Figure 7.8 that the signal output changes even for relatively slow temperature variations. However, the total variation of about $6 \%$ occurs for a total temperature change of nearly $600^{\circ} \mathrm{F}$. 


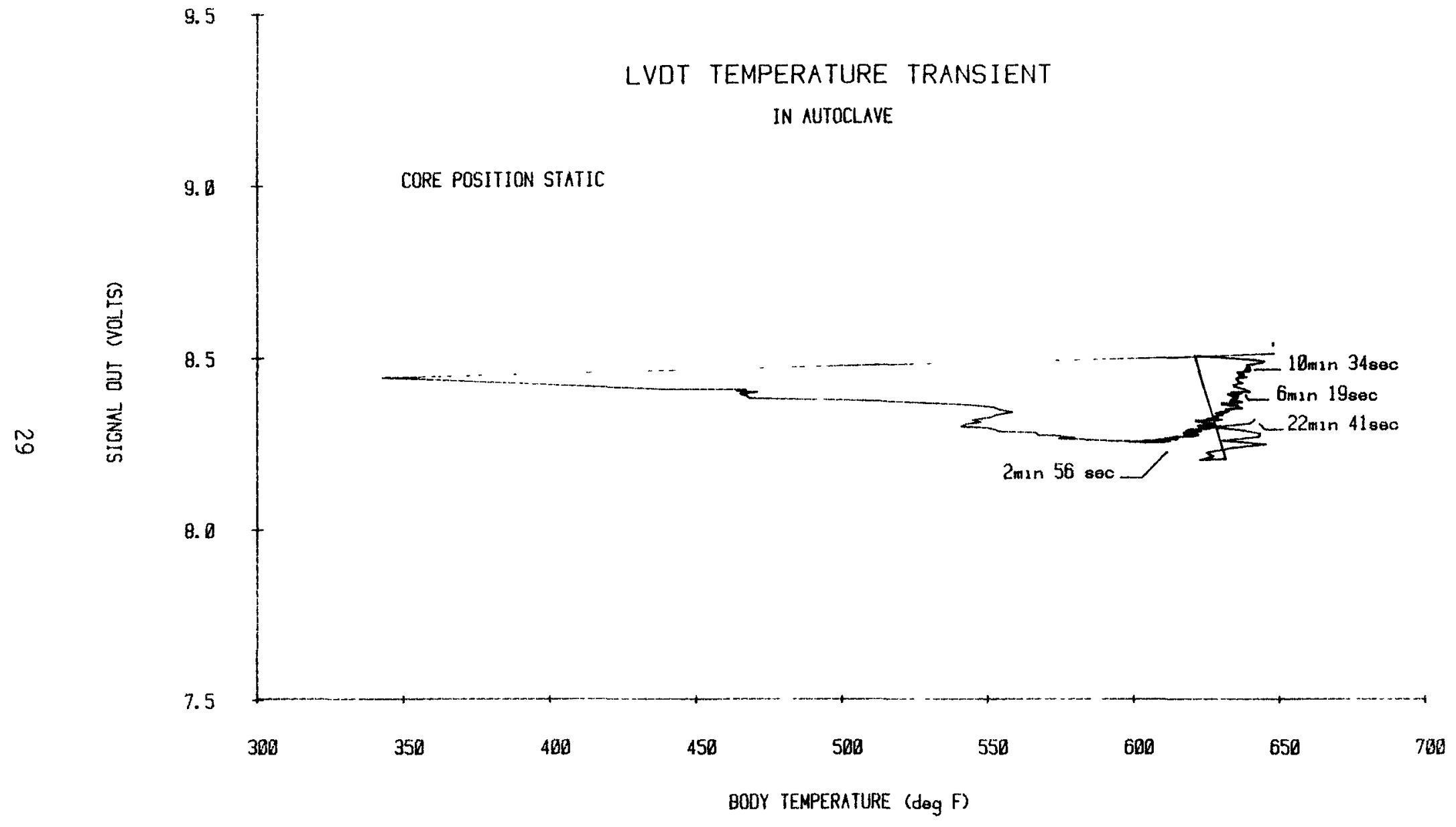

FIGURE 7.6. Variation of Signal Output of Qualification Sensor for Autoclave Blowdown. 


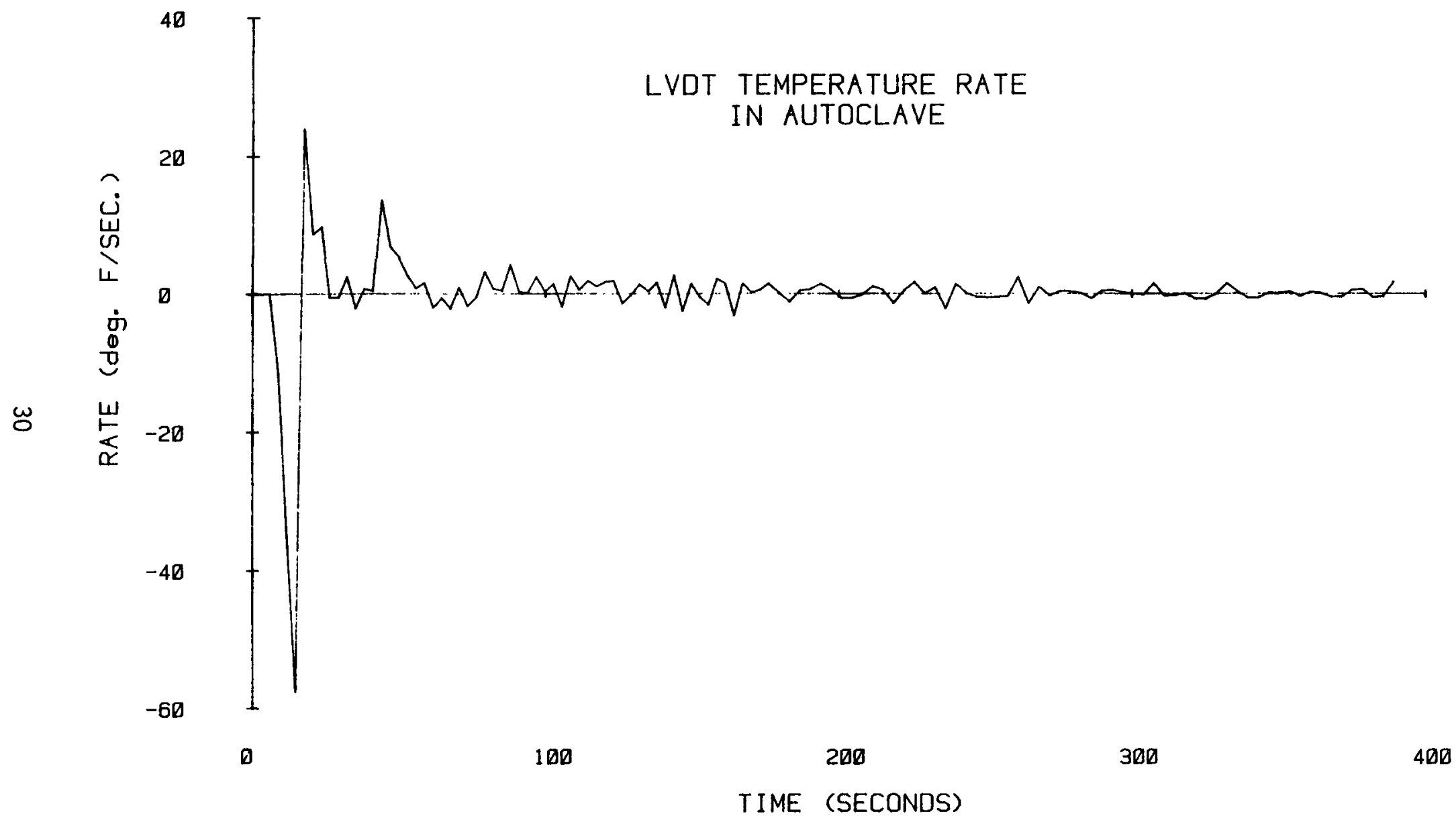

FIGURE 7.7. Rate of Temperature Change for Blowdown Test of Figure 7.6. 


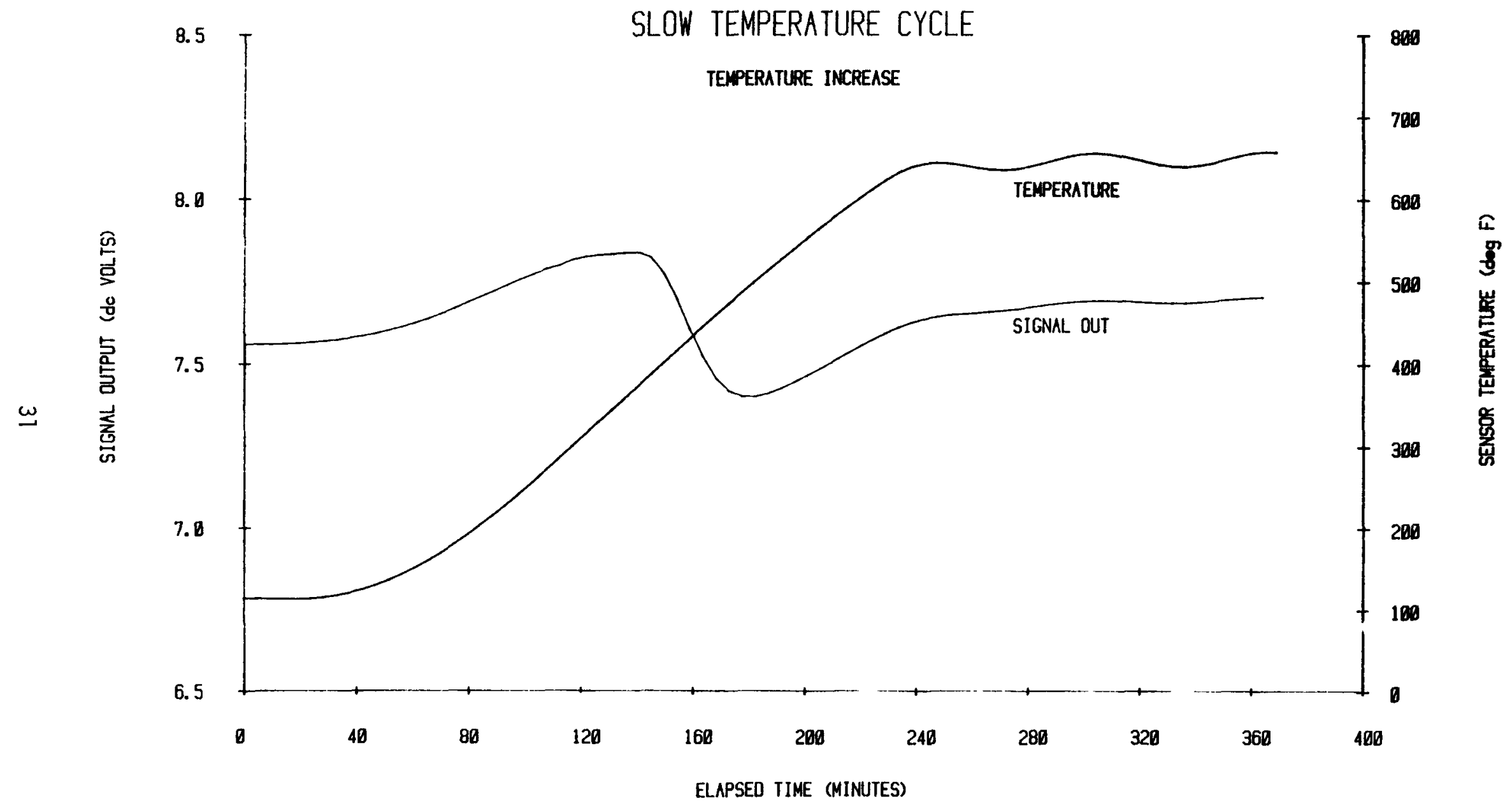

FIGURE 7.8. Variation of Signal Output for Slow Increase of Sensor Temperature. 
After a period of 200 hours, during which multiple transient and steady state tests occurred, the sensor exhibited insignificant signal drift as determined by comparison of data at the beginning and conclusion of the test period.

During time intervals between blowdown tests, the sensor signal output was measured to determine its stability for relatively long time durations. For the interval, sensor temperature was maintained constant at about $650^{\circ} \mathrm{F}$. Signal output of the sensor for time periods of nearly 50 hours exhibited minor variations with the test temperature similar to the characteristic shown in Figure 7.9. Smal1 discontinuities of the temperature appear in plotted data because of a short time lapse (when the temperature changes) for acquisition of consecutive data files.

To assure mechanical integrity of the LVDT envelope, a static pressure of $3125 \mathrm{psig}$ is applied for a period of 15 minutes. During the time period the output signal remained nearly constant. Post test visual examination verified the absence of structural damage. Further, during subsequent vibration tests the sensor responded normally with negligible correlation of signal output with either applied vibration frequencies or accelerations.

\subsection{Time Response}

The time required for the sensor to respond to rapid displacements was determined by mechanically displacing the sensor core and simultaneously recording the output voltage. Even though the input displacement does not occur discontinuously, movement is rapid enough to verify an instrumentation response time of 21 milliseconds. The specified value of less than $100 \mathrm{milli-}$ seconds is easily satisfied. Figure 7.10 graphically depicts the variation of output signal as the core is displaced from one to the other extreme of the range. 


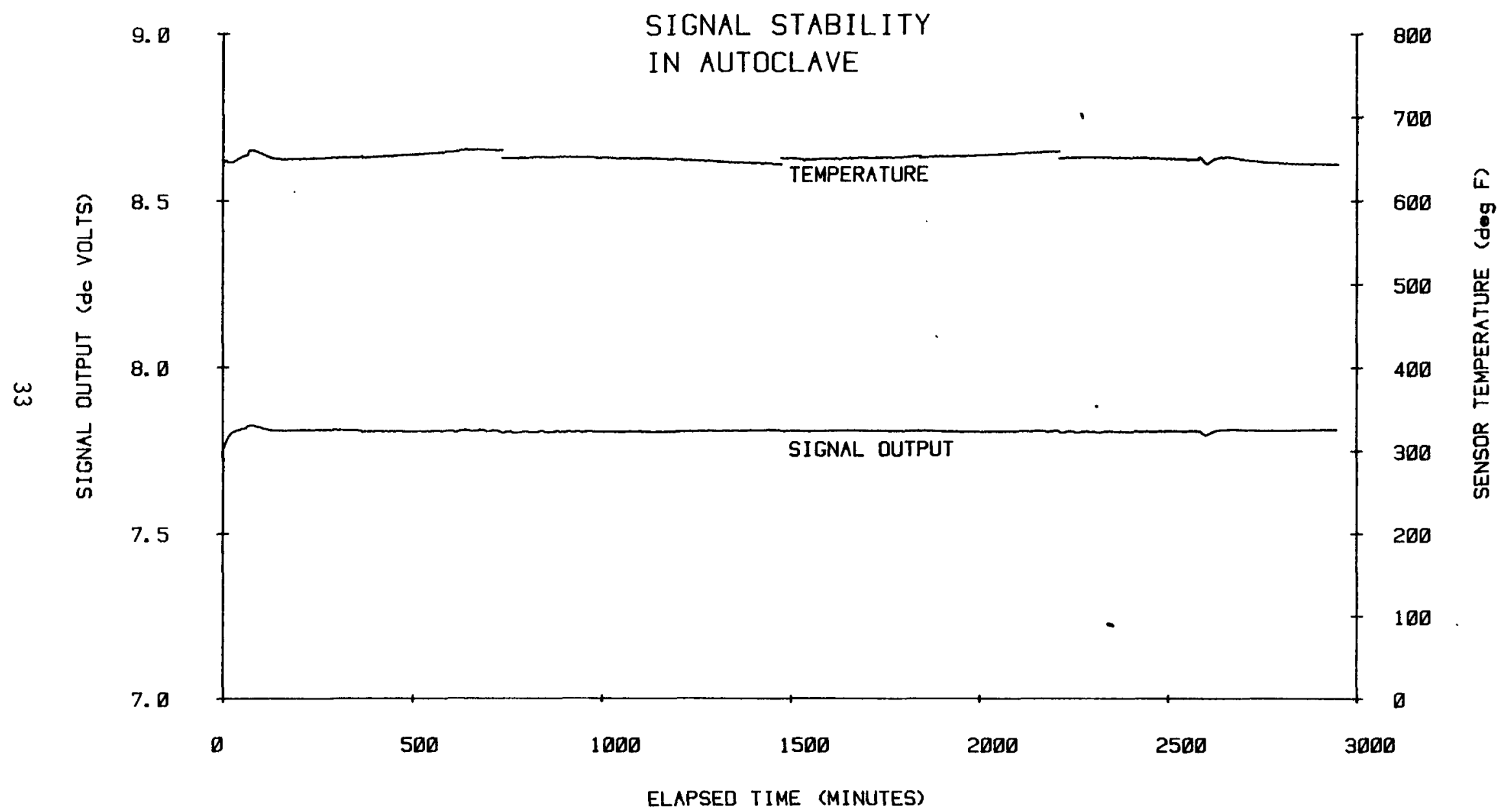

FIGURE 7.9. Long Term Signal Output Stability for LVDT in Autoclave at $650^{\circ} \mathrm{F}$. 


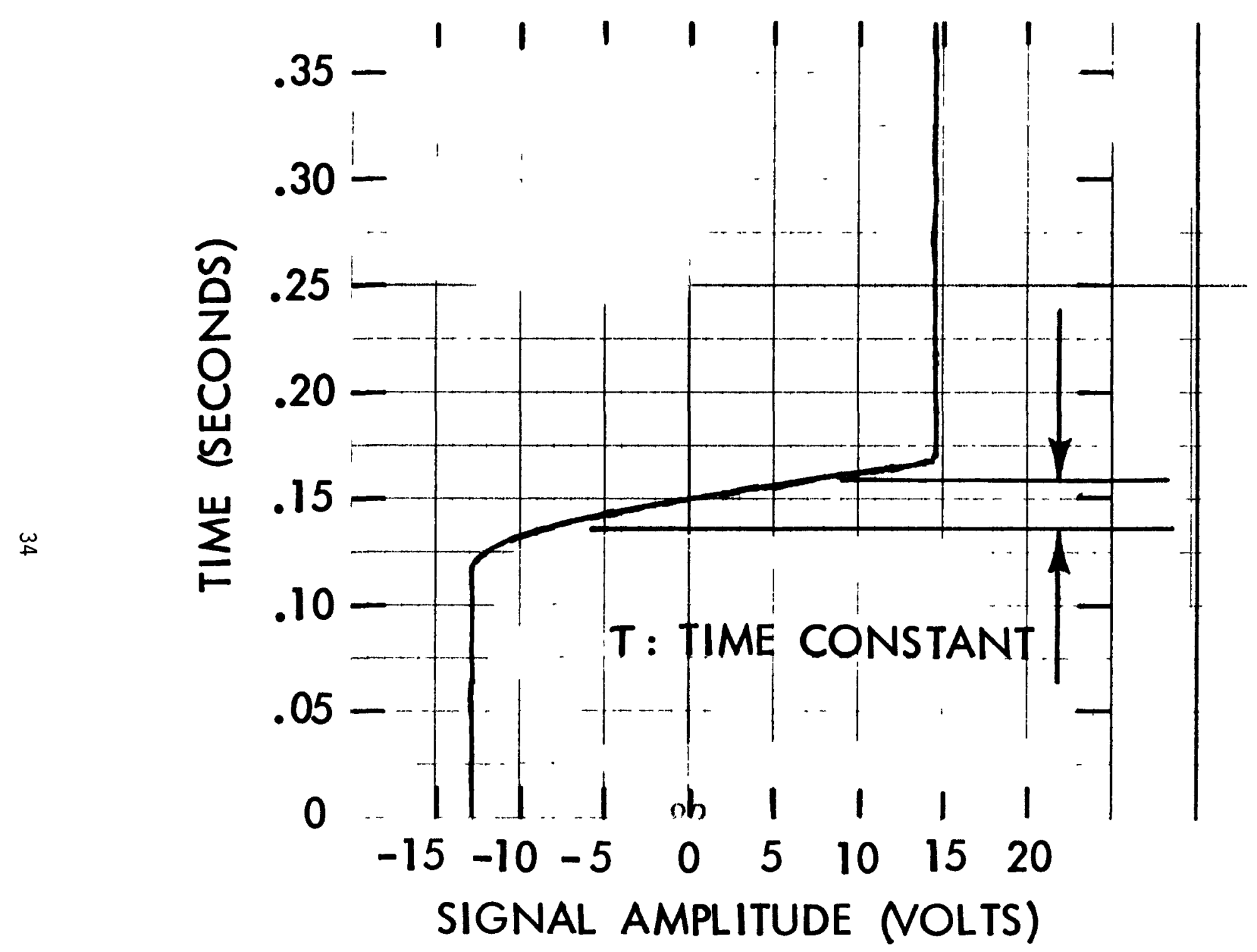

FIGURE 7.10. Response of the Sensor for Rapid Displacement of the Sensing Core. T Represents $10 \%$ to $90 \%$ Time Response.

HEDL 7907-091 


\subsection{Quench Test}

Another method of subjecting the sensor to extremely rapid temperature changes involves placement of the transducer in an $800^{\circ} \mathrm{F}$ environment for at least 100 seconds followed immediately by a quench in water at $200^{\circ} \mathrm{F}$. For this test, the sensor was placed in a vertically oriented oven at $800^{\circ} \mathrm{F}$. After at least 100 seconds at $800^{\circ} \mathrm{F}$, the sensor was lowered into a 2-liter bath of $200^{\circ} \mathrm{F}$ water. Figure 7.11 indicates the variation of and Figure 7.12 the time sequence of signal output for the temperature quench. Qualification sensors survived and continued normal operation after this very severe test.

\subsection{Irradiation Tolerance}

To assess stability of operation of the LVDT displacement sensor in the nuclear environment specified for LOFT instrumentation, consider effects which could disrupt nomal operating characteristics. For continued proper operation, the voltages induced into the two secondary coils must remain reproducible for specific repeated axial displacements of the sensing core with respect to the coils. The sum and difference voltages induced into the secondary coils act as inputs to the signal conditioning electronics. A control signal derived from the sum voltages adjusts the primary coil signal excitation to maintain the sum of secondary voltages constant, thereby reducing transducer operational dependence on effects such as excitation, pressure and temperature variations. The coil difference voltage remains linearly proportional to relative displacement of the core with the transducer coils.

Effects possibly detrimental to the continued reliable operation of the transducer in a neutron and gamma radiation environment pertain to physical and/or electrical instability of the materials of construction as noted in Table 4.1. Physical and electrical properties of each of the materials in a radiation field have been previously investigated. ${ }^{2-8}$ In general, the following noted changes of the transducer could result in operational malfunction. 


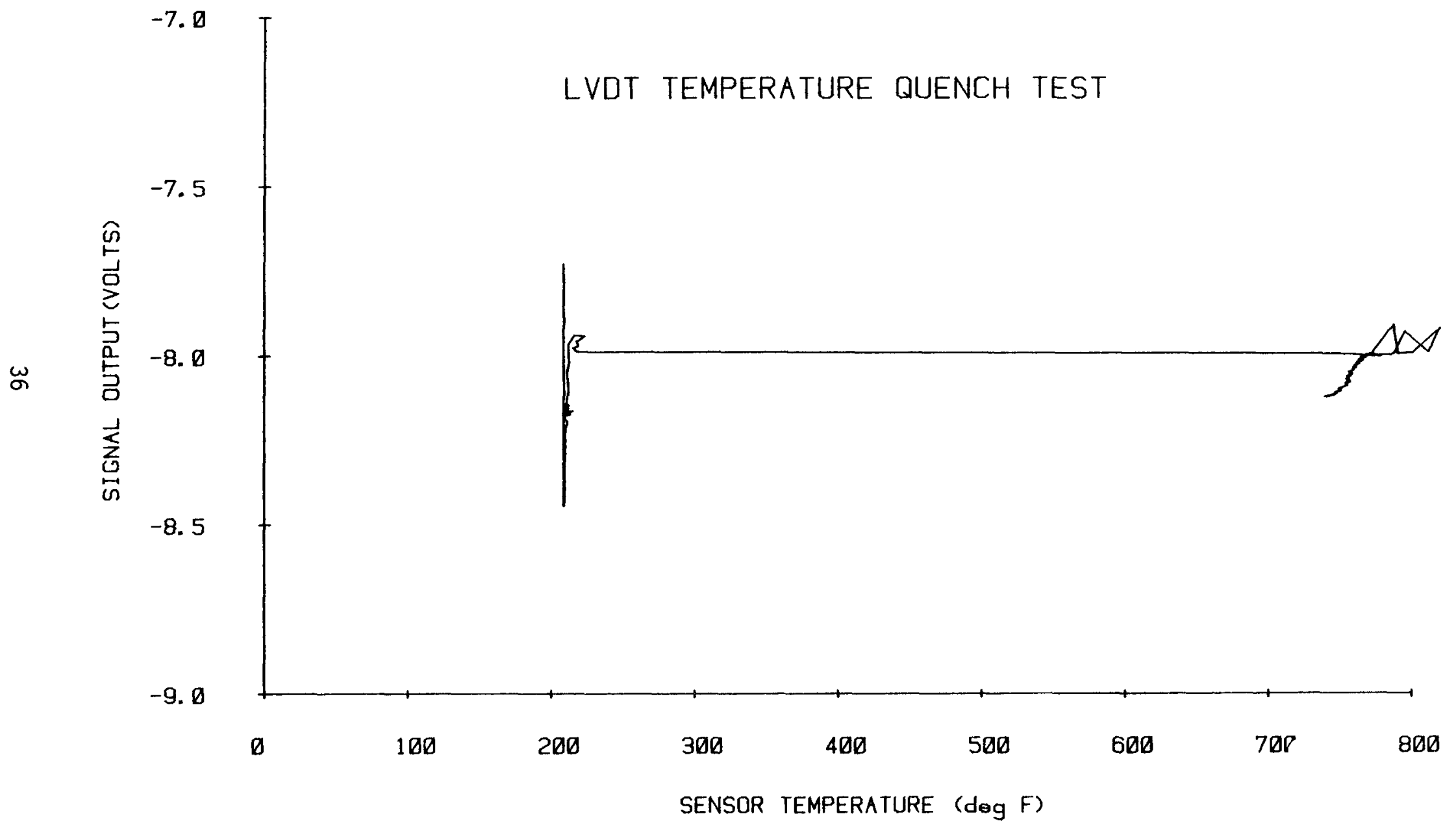

FIGURE 7.11. Displacement Sensor Output Signal Variation for Quench of Sensor Temperature from 800 to $200^{\circ} \mathrm{F}$. 


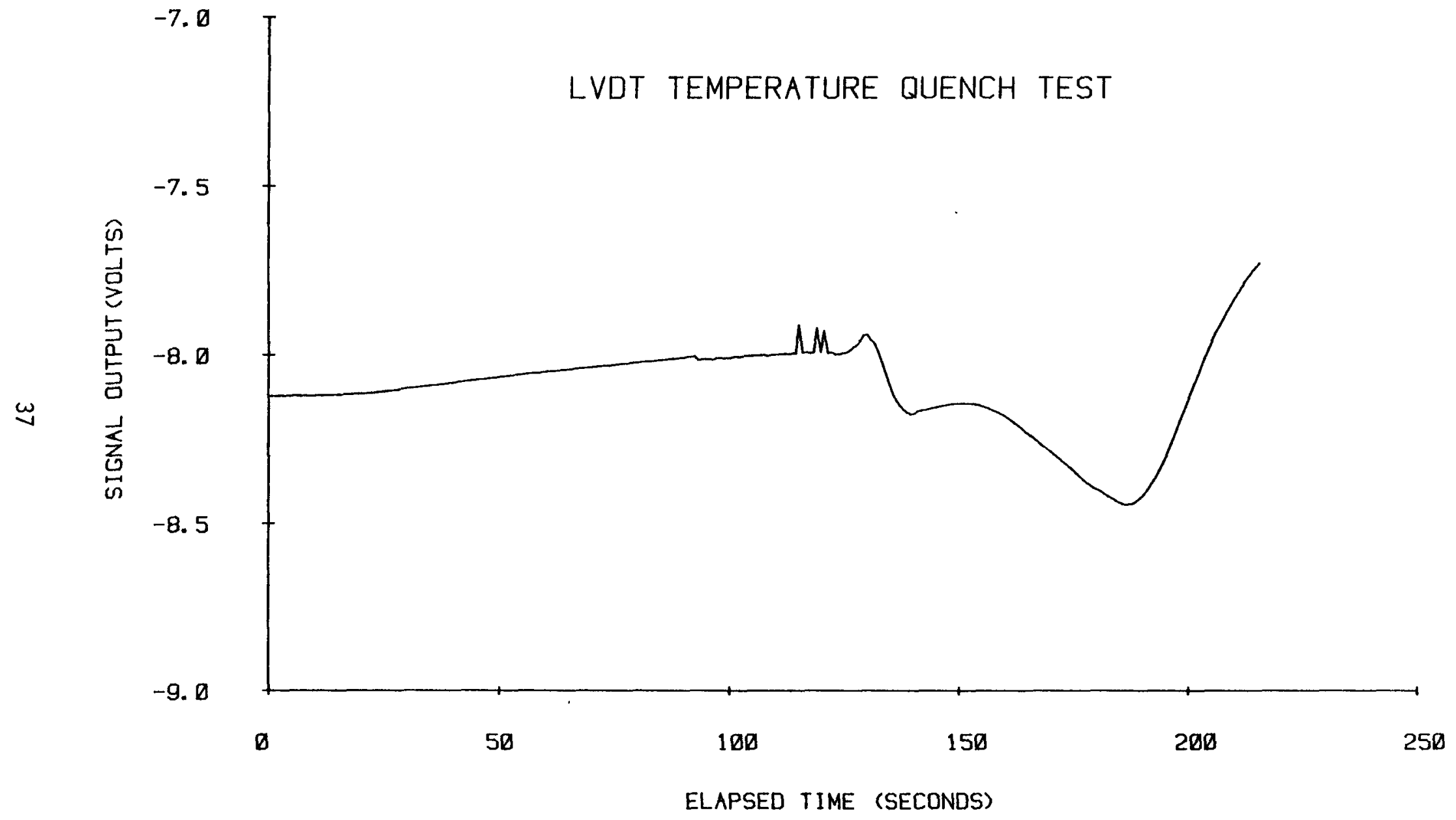

FIGURE 7.12. Time Sequence of Signal Output for Temperature Quench of Figure 7.11. 
- Resistance change of coil wire.

- Variation of the effective diameter of either the primary or secondary coils.

- Change of magnetic permeability of the soft iron sensing core.

- A relative and permanent displacement of the core with respect to the transducer coils.

Each of the above noted characteristic changes are described.

\subsubsection{Coil Resistance Changes}

The primary and two secondary LVDT coils of copper with $0.02 \%$ zirconium are wound on a common cylinder of Inconel 625 and 94\% alumina ceramic. Changes of coil resistance resulting from any external stimulus cause an instantaneous change of the sum of secondary coil output voltage. However, this voltage is used as a control to adjust excitation of the primary coil sufficient to yield a constant secondary sum voltage. As a consequence, changes of coil resistance caused by radiation will not adversely affect operation of the sensor because of the described temperature compensating circuitry of the signal conditioning system.

\subsubsection{Core Stability}

The sensor core of the LVDT consists of a solid soft iron cylinder swaged inside an Inconel 625 tube. Inductive signal coupling between the primary and secondary coils relates to the effective magnetic permeability of the soft iron core. Any changes of permeability result in control signal variations to the primary coil excitation circuit, thereby compensating for any changes of core permeability. Consequently, radiation-induced variations of magnetic permeability should not result in off-normal operation of the displacement sensor. Furthermore, a wrap of insulation (ceramic paper) placed between the soft iron core and the swaged Inconel sheath will not cause operational difficulties because of its stability and entrapment within the closed Inconel cylinder. 


\subsubsection{Dimensional Stability}

Radiation-induced dimensional changes of transducer components can result in effective coil diameter variations or in relative axial displacements of transducer components. However, metals of construction exhibit volume expansions of at most $\sim 1 \%$ for fluences specified $\left(2 \times 10^{13} \mathrm{nV}\right.$ for 1000 hours or $7.2 \times 10^{19} \mathrm{nvt}$ ). As a result we can expect linear expansions (note Appendix A) for isotropic materials on the order of

$$
\begin{aligned}
& \frac{\Delta L}{L}=\frac{-3 \pm 9 \sqrt{12(.01)}}{6} \text { or } \\
& \frac{\Delta L}{L}=\frac{-3 \pm \sqrt{9.12}}{6}=.0033
\end{aligned}
$$

or about $0.3 \%$. As the effective coil diameter increases a slight change of secondary induced voltage will occur. However, because of operation of the signal conditioning, the primary excitation will be adjusted to compensate for secondary voltage changes.

\subsubsection{Relative Displacements}

An apparent shift of the zero core displacement could occur if the midpoint position of the secondary coils relative to the core midpoint changed due to radiation effects. However, for maximum possible differential expansion due to radiation effects, the zero shift of $(.0033 \times 3=.01$-inch $) 0.01$ inch corresponds to an introduced error of $1 \%$ of full scale, a quite small error based on a very pessimistic assumption of maximum differential expansion.

In addition to the known stability (as verified by the HEDL materials technologists and by the referenced experimenters) of materials of construction, an LVDT of similar construction has been used in the Halden reactor at fluences up to $10^{20}$ nvt. 9,10 Their experience confirms stable operating characteristics of the LVDT persist even without use of self-compensating 
electronics and at accumulated doses in excess of that specified for LOFT. Use of compensated signal conditioning electronics as specified for the LOFT LVDT should further increase its operating stability.

Furthermore, one qualification transducer was placed in a HEDL irradiation facility with a ${ }^{60}$ Co gamma source of $\sim 1 \times 10^{7} \mathrm{R} / \mathrm{hr}$. For an accumulated dose of $3 \times 10^{10} \mathrm{R}$, output of the sensor (core position static) has remained stable within $\pm 1 \%$, accounting for all sources of instability. The irradiation test will be continued to a greater fluence. 


\section{APPENDIX A}

\section{RELATION BETWEEN LINEAR DIMENSION AND VOLUMETRIC SWELLING}

$L_{1}$ : initial length

$\mathrm{L}_{2}$ : final length

$v_{2}$ : final volume

$v_{1}$ : initial volume

$L_{2}=L_{1}+L$

$V_{2} \alpha L_{2}^{3}=\left(L_{1}+\Delta L\right)^{3}$

$\frac{\Delta V}{V_{1}}=\frac{V_{2}-V_{1}}{V_{1}}=\frac{\left(L_{1}+\Delta L\right)^{3}-L_{1}^{3}}{L_{1}^{3}}$

$\frac{\Delta V}{V_{1}}=\frac{L_{1}^{3}+3 L_{1}^{2} \Delta L+3 L_{7} \Delta L^{2}+\Delta L^{3}-L_{1}^{3}}{L_{1}^{3}}$

$\frac{\Delta V}{V_{1}}=\frac{3 L_{1}^{2} \Delta L+3 L_{1} \Delta L^{2}+\Delta L^{3}}{L_{1}^{3}}=\frac{3 \Delta L}{L_{1}}+3\left(\frac{\Delta L}{L_{1}}\right)^{2}+\left(\frac{\Delta L}{L_{1}}\right)^{3}$ Assume a fractional change of $\frac{\Delta V}{V}$. Also $\left(\frac{\Delta L}{L_{l}}\right)^{3}$ is much smaller than other
equation terms.

$$
\therefore 3\left(\frac{\Delta L}{L_{1}}\right)^{2}+3 \frac{\Delta L}{L_{1}}=\frac{\Delta V}{V}=\Delta
$$

and

$\frac{\Delta L}{L_{1}}=\frac{-3 \pm \sqrt{9+12 \Delta}}{6}$ 


\section{REFERENCES}

7. T. Roger Billeter "Displacement Sensor for Measurement of Fuel Rod Elongation in the LOFT Reactor", HEDL-TC-1517, September 1979.

2. N. S. Kostyukov, "Insulating Materials for Work in Thermal Neutron Fluxes", translated from Teplofizika Vysokikh Temperature, Vol. 5, pp 361-366, March 1967.

3. G. F. Hurley, "Structural Effects in Neutron Irradiation of Insulating Ceramics", LA-UR-76-1131, May 17, 1976.

5. H. J. Busboo, R. R. Asamoto, "Evaluation of Physical and Mechanical Properties of Type 304 Stainless Steel After Irradiation to $3.9 \times 10^{22}$ $\mathrm{n} / \mathrm{cm}^{2}$ Total Fluence", GEAP-13571, February 1970.

6. A. L. Ward, et. al., "Irradiation and Thermal Effects on the Tensile Properties of Inconel Alloy 718", HEDL-SA-853, May 1976.

7. Final Report on GTR-18 Test to Determine High Temperature Radiation Effects on Structural Materials, RN-S-0398, July 1967.

8. Proceedings of the Conference on Nuclear Applications of Nonfissionable Ceramics, edited by Alvin Boltax, J. H. Handwerk, May 9-11, 1966.

9. B. Aarset, "In-Core Measurements and Accuracies at HBWR", OECD Ha1den Reactor Project, Norway, HPR-III, July 1969.

10. K. Schenk, "Development of Differential Transformers for Measurement of In-Core Fuel Elongation", OECD Halden Reactor Project, Halden, Norway, HPR-70, January 1967. 
DOE/RL (3)

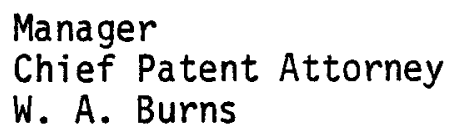

\section{DOE/FFTFPO (1)}

R. A. Graham

\section{EG\&G (9)}

P.0. Box 1625

Idaho Falls, ID 83415

R. E. Williams (7)

T. G. Faucett

G. B. Shul1

NRC/HQ (5)

R. VanHouten

W. V. Johnston

G. D. McPherson

N. N. Kondic

Y. Y. Hsu

$\underline{\mathrm{NRC} / \mathrm{ID}}$ (1)

P. 0. Strom

HEDL (12)

T. R. Billeter (2) W/A-56

R. L. Brown

W/A132

C. P. Cannon

W/A-56

C. T. Schaedel

W/A-46

E. M. Sheen

$W / A-56$

J. L. Stringer

$W / A-56$

J. M. Yatabe

$W / C-22$

Central Files (2)

$W / C 110$

Pub1. Services (2) W/C115 